\title{
INUNDACIONES DE SEPTIEMBRE DE 2019 EN LA VEGA BAJA DEL SEGURA. LA OPORTUNIDAD DEL PLAN "VEGA RENHACE"
}

\author{
Jorge Olcina Cantos \\ Instituto Interuniversitario de Geografía, Universidad de Alicante Campus \\ de San Vicente del Raspeig s/n, 03690 Alicante \\ jorge.olcina@ua.es
}

Resumen: El litoral mediterráneo español es una región-riesgo frente a las inundaciones en el contexto europeo. El río Segura en su tramo medio y bajo ha sido protagonista de eventos catastróficos de inundación de forma frecuente en el último siglo y medio. El último episodio ocurrido, en septiembre de 2019, tras la canalización del curso fluvial después de la riada de 1987, ha puesto de manifiesto que las soluciones estructurales no son suficientes para la reducción del riesgo y son necesarias medidas integrales para la ordenación y gestión sostenible del territorio. Todo ello en un contexto climático de incertidumbre, que manifiesta ya los efectos del calentamiento atmosférico, en el que la modelización señala la mayor frecuencia de desarrollo de eventos meteorológicos extremos. El plan Vega Renhace es una apuesta estratégica para la adaptación de la comarca del Bajo Segura al cambio climático y la mejora de la resiliencia social, económica y territorial ante la elevada peligrosidad natural existente.

Palabras clave: Inundaciones, Vega Baja del Segura, cambio climático, plan estratégico, adaptación, resiliencia.

September 2019 flood episode in vega baja del Segura (Alicante, Spain). The opportunity of the "Vega Renhace" plan

Abstract: The Spanish Mediterranean coast is an European flood risk-region. The Middle and Lower Segura River has been protagonist of frequently catastrophic flood events in the last century and a half. The last episode that occurred, in September 2019, after the channelization of the river course

Recibido: 08-01-2021. Aceptado: 05-02-2021. 
after the 1987 flood, has shown that structural solutions are not enough to reduce risk and comprehensive measures are necessary for sustainable planning and management in this territory. All this in a climate context of uncertainty, which already manifests the effects of atmospheric warming, in which climate modelling indicates the higher frequency of development of extreme meteorological events. The Vega Renhace Plan is a strategic bet for the adaptation of the Bajo Segura territory to climate change and the improvement of social, economic and territorial resilience due to high natural hazards existing.

Keywords: Floods, Vega Baja of Segura river, climate change, strategic plan, adaptation, resilience.

\section{Introducción. Inundaciones en el Bajo Segura: un territorio de riesgo}

La comarca Vega Baja del Segura es un territorio de riesgo ante diversos peligros naturales. Muy especialmente los extremos del agua (inundaciones y sequías) otorgan un elevado grado de riesgo en el contexto europeo, debido a la elevada frecuencia de desarrollo y al alto grado de ocupación humana de este espacio geográfico. Forma parte del área más meridional de la provincia de Alicante, en lo que algunas divisiones comarcales han denominado, en sentido amplio, el Bajo Segura. Está integrada en la región climática del Sureste siendo la más seca de la Península Ibérica y de Europa (Gil Olcina \& Olcina Cantos, 2017). El denominador común de sus observatorios es la poquedad de precipitaciones, con duras y prolongadas sequías, sin perjuicio de esporádicos diluvios de elevada, y hasta excepcional, intensidad horaria (Gil Olcina \& Olcina Cantos, 2017). Ejemplo de ello ha sido el episodio de septiembre con la gota fría o DANA de 2019, alcanzando intensidades y volúmenes de precipitación muy elevadas, característica de las lluvias torrenciales del mediterráneo, llegando a superar los valores medios de precipitación anual.

Es el sector más árido, con un periodo seco estival que se extiende a algunos meses de la primavera y del otoño, de manera que llega a tener una larga duración (5-6 meses) e intensidad. Las lluvias medias anuales llegan a valores inferiores de $300 \mathrm{~mm}$ (Orihuela, $317 \mathrm{~mm}$; Guardamar del Segura, $287 \mathrm{~mm}$ y Torrevieja, $271 \mathrm{~mm}$ ). Los meses más favorables para las lluvias son los de otoño y primavera, con picos acusados (Gil Olcina \& Olcina Cantos, 2017). El número de días de lluvia al año es escaso y oscila entre 30 y 50 (Canales et al., 1995). Sin embargo, los días de lluvia se están reduciendo, por el proceso de calentamiento térmico planetario actual, concentrando, en menos días, mayores volúmenes e intensidades de precipitación. Se trata de un proceso que se presenta como un efecto de la hipótesis de cambio climático por efecto invernadero de causa antrópica, que, en efecto, comienzan a manifestar evidencias en los elementos cli- 
máticos del litoral mediterráneo español (Olcina, 2018). La comarca de la Vega Baja del Segura engloba espacios geográficos diversos, con marcados contrastes entre huerta, campo, costa e interior, profundamente antropizados desde época histórica, caracterizados geográficamente por la presencia del río Segura en su tramo bajo, que ha sido fuente de riqueza y, en ocasiones, también de desastres. El río Segura es, por tanto, el elemento geográfico que da personalidad a la comarca. Un río de comportamiento mediterráneo desde su tramo medio hasta la desembocadura, con un caudal generalmente escaso que, sin embargo, experimenta crecidas desaforadas con ocasión de las lluvias torrenciales que se producen en el Sureste Ibérico. La lucha con y por el agua ha sido una constante histórica en las tierras de la Vega Baja del Segura; déficit y exceso, sin apenas término medio. Aun así, las gentes de la comarca han sabido tejer unas actividades económicas, que han evolucionado con el paso del tiempo, y que han permitido un desarrollo notable, aunque no exento de amenazas y de riesgos.

El río Segura y sus tributarios tienen una historia repleta de extremos hidrológicos (sequías e inundaciones) a los que han tenido que adaptarse los habitantes de su cuenca. El trazado de la red de riego de la Vega Baja, de época islámica, con antecedentes romanos, es una muestra de aprovechamiento exhaustivo del agua para uso agrario en un territorio con déficit de recursos propios de agua. Y a ello hay que sumar los terremotos, como peligro natural de impronta territorial en la comarca de la Vega Baja del Segura. Este territorio forma parte de una serie de fallas activas en el sector de contacto de las placas tectónicas de Europa (sector ibérico) y de África. Es una zona de sismicidad activa, con movimientos diarios de baja magnitud, pero que no desconoce grandes terremotos que condicionaron el futuro de las poblaciones de la comarca como ocurrió el 21 de marzo de 1829 (Silva et al., 2019). Por tanto, la mejora de la "resiliencia" de este territorio debe tener en cuenta su carácter de espacio con alta peligrosidad natural que debe adaptar siempre sus actividades y usos del suelo a esta condición (Tabla 1).

Tabla 1. Elementos territoriales que convierten a la Vega Baja del Segura en un espacio con riesgo natural elevado y vulnerable a los efectos del cambio climático

\begin{tabular}{|l|l|}
\hline Aspectos físicos & Aspectos humanos \\
\hline - Río Segura y sus tributarios con & - Ocupación histórica del territorio \\
comportamiento torrencial & - Intensidad de usos del suelo para fines diversos \\
- Escasez natural de recursos hídricos & (agrícolas, industriales, urbano-turísticos) \\
- Antigua zona palustre & - Población diversa, con protagonismo \\
- Sistemas de fallas tectónicas activas & importante de residentes extranjeros \\
- Temporales de levante enérgicos & - Uso intensivo de los escasos usos del agua \\
- Efectos ya evidentes del actual proceso & - Red de riegos que puede actuar como difusora \\
de calentamiento climático & de las inundaciones \\
\hline
\end{tabular}

Fuente: Elaboración propia. 
La Vega Baja del Segura ha vivido numerosos momentos de inundación provocados por la reactivación de los barrancos y ramblas, que descienden de los relieves más próximos, y de los desbordamientos del río Segura. La adversidad ha sabido convertirse en oportunidad casi siempre con medios propios, con el propio esfuerzo de los habitantes de la comarca y, en grandes eventos de inundación, con ayuda externa en forma de inversiones y actuaciones que permitieran recuperar la normalidad y planes orientados a reducir el riesgo. El desbordamiento de mayores consecuencias socioeconómicas y territoriales de la historia contemporánea tuvo lugar el 14-15 de octubre de 1879, la conocida "riada de Santa Teresa". Desde la década de los años cuarenta del pasado siglo, la vega baja del Segura ha conocido inundaciones muy destacadas que darán lugar a propuestas diversas de solución, hasta el desarrollo de la riada de noviembre de 1987 que motivará la aprobación por vía de urgencia del Plan de Defensa de Avenidas de la Cuenca del Segura (1987); esta fecha establece el inicio cronológico del presente apartado dedicado a analizar los episodios de inundación ocurridos en los últimos treinta años en la Vega Baja del Segura. La Tabla 2 incluye un resumen del impacto de esas inundaciones tanto a nivel social como económico. Se incluyen los caudales máximos registradosen aforo que han circulado por el río Segura en momentos de crecida y, en ocasiones, desbordamiento.

Debido a los efectos económicos y territoriales causados por estos episodios de crecida y desbordamiento del río Segura en su tramo bajo, se han ido planteando medidas de defensa, generalmente orientadas a la construcción de encauzamientos en el curso principal o en los tributarios de la parte baja de la cuenca. Destacan las propuestas y actuaciones desarrolladas desde 1941 por el Ministerio de Obras Públicas y cuya relación incluye las propuestas de: a) febrero de 1947 con la cementación de algunos márgenes del río Segura; b) septiembre de 1947, "Obras de defensa en la margen izquierda del Segura"; c) octubre de 1948, "Proyectos de obra de defensa en la cuenca del Segura"; d) octubre de 1957, cuando se plantea la construcción del pantano de Santomera; e) diciembre de 1965, "Proyecto de acondicionamiento del Segura desde aguas arriba de Oribuela hasta su desembocadura en Guardamar"; y e) septiembre y octubre de 1966 cuando se sigue demandando el encauzamiento del río Segura. A partir del año 1966, se deja de hablar de las obras de defensa del río Segura debido al protagonismo que cobraran las sequías y su solución proyectada por el gobierno de la dictadura: el trasvase Tajo-Segura. No obstante, los episodios de inicios de los años setenta del pasado siglo vuelven a evidenciar los problemas de desbordamiento del Segura en su tramo final y surgen nuevas demandas de realización de obra hidráulica. Así, con la riada de octubre de 1972, las medidas de defensa tomadas en el río Segura en el año 1947 se ven insuficientes y superadas por ésta. Ocurre lo mismo en octubre de 1973, episodio muy destacado que causaría un total de 200 fallecidos en Murcia, Almería y Granada. Tras cada medida de defensa adoptada el río conseguía desbordarse de nuevo, lo que llevó a la población a hacer hincapié continuo en el encauzamiento del río Segura como medida urgente. A raíz de este episodio se elaboraría el Plan de Defensa de Avenidas de la cuenca del Segura (1977) que, sin embargo, quedaría guardado en un cajón durante años, a la espera de una coyuntura económica más favorable para su implantación. 
Tabla 2. Inundaciones históricas en la Vega Baja del Segura desde 1946 a 2020

\begin{tabular}{|c|c|c|c|c|c|c|c|}
\hline $\begin{array}{l}\text { Fecha } \\
\text { (Días/mes) }\end{array}$ & Año & $\begin{array}{l}\text { Precipitación } \\
\text { Oribuela } \\
\left(\mathrm{l} / \mathrm{m}^{2}\right)\end{array}$ & $\begin{array}{l}\text { Aforo } \\
\text { Caudal } \\
\left(\mathrm{m}^{3} / \mathrm{s}\right)\end{array}$ & Inundación & $\begin{array}{l}\text { Pérdidas } \\
\text { bumanas }\end{array}$ & $\begin{array}{l}\text { Pérdidas } \\
\text { económicas }\end{array}$ & $\begin{array}{l}\text { Superficie } \\
\text { inundada } \\
\text { ba. }\end{array}$ \\
\hline $19-22 / 04$ & 1946 & 109,4 & 500 (Orihuela) & Segura y otros & 0 & $34.558 €$ & 23.600 \\
\hline $25-29 / 09$ & 1947 & 75 & 750 (Orihuela) & Segura y otros & $\begin{array}{l}14 \\
\text { (Santomera) }\end{array}$ & $300.506 €$ & 1.654 \\
\hline $19-23 / 10$ & 1948 & 49,1 & 950 (Orihuela) & Segura y otros & 0 & Incalculables & 894 \\
\hline $14-18 / 02$ & 1949 & 26,2 & 700 (Orihuela) & Segura y otros & 0 & > año 1946 & 1.000 \\
\hline $22-24 / 04$ & 1951 & 52 & - & Segura & 0 & - & - \\
\hline $11-16 / 10$ & 1957 & - & 155 (Rojales) & Segura & 0 & - & - \\
\hline $14-19 / 09$ & 1962 & 19,5 & - & Segura y Abanilla & 0 & $240.405 €$ & 2.236 \\
\hline $22-23 / 12$ & 1964 & 32 & - & Segura y otros & 0 & $>780 €$ & $>950$ \\
\hline $09-10 / 12$ & 1965 & 126 & 200 (Orihuela) & $\begin{array}{l}\text { Abanilla, Derramador } \\
\text { y Segura }\end{array}$ & 0 & $540.911 €$ & 2.012 \\
\hline $11-15 / 09$ & 1966 & 36 & - & Abanilla & 0 & $901.518 €$ & 1.788 \\
\hline $10-12 / 10$ & 1966 & 55 & 300 (Rojales) & $\begin{array}{l}\text { Abanilla, Derramador } \\
\text { y Segura }\end{array}$ & 0 & - & - \\
\hline $14-15 / 02$ & 1967 & 55 & - & $\begin{array}{l}\text { Derramador y } \\
\text { Abanilla }\end{array}$ & 0 & - & 134 \\
\hline $17-19 / 04$ & 1967 & 36 & - & Abanilla & 0 & $90.151 €$ & 1.118 \\
\hline $03-05 / 05$ & 1967 & - & - & Abanilla & 0 & - & - \\
\hline $01-03 / 02$ & 1968 & 52 & - & Abanilla y Derramador & 0 & - & - \\
\hline $11-12 / 06$ & 1968 & 14 & - & Abanilla & 0 & - & - \\
\hline $23-25 / 10$ & 1971 & 27,5 & - & Derramador y Abanilla & 0 & $\begin{array}{l}3.666 .174 € \\
\text { (prov. Alicante) }\end{array}$ & 2.955 \\
\hline $17-19 / 10$ & 1972 & 132 & 350 (Orihuela) & Segura y otros & 0 & $436.084 €$ & 2.873 \\
\hline $17-19 / 10$ & 1973 & 19 & 354 (Orihuela) & Segura y otros & $\begin{array}{l}200 \text { (Murcia, } \\
\text { Granada, } \\
\text { Almería) }\end{array}$ & $150.253 €$ & 2.727 \\
\hline $19-20 / 10$ & 1982 & 67,8 & 115 (Orihuela) & Segura y otros & 1 (Rojales) & - & - \\
\hline $01-04 / 10$ & 1986 & 37,6 & 380 (Orihuela) & Segura y otros & $\begin{array}{l}1 \text { (La Zenia) } \\
1 \text { (Cabo Roig) } \\
3 \text { (Murcia) }\end{array}$ & $2.103 .542 €$ & - \\
\hline $13-14 / 10$ & 1986 & 40 & 439 (Orihuela) & Segura y otros & 1 (Orihuela) & $>2.104 .107 €$ & 700 \\
\hline $04-08 / 11$ & 1987 & 316 & 400 (Orihuela) & Segura y otros & $\begin{array}{l}2 \text { (Vega Baja) } \\
210 \\
\text { desaparecidos } \\
\text { (Vega Baja) } 5 \\
\text { Pilar de la } \\
\text { Horadada }\end{array}$ & $\begin{array}{l}19.704 .969 € \\
\text { Segura }\end{array}$ & $\begin{array}{l}\text { Toda la Vega } \\
\text { Baja del }\end{array}$ \\
\hline 04-09/09 & 1989 & 100 & 200 (Orihuela) & Segura y otros & 0 & $420.709 €$ & $\begin{array}{l}\text { Gran parte } \\
\text { de la Vega } \\
\text { Baja }\end{array}$ \\
\hline
\end{tabular}




\begin{tabular}{|c|c|c|c|c|c|c|c|}
\hline $\begin{array}{l}\text { Fecha } \\
\text { (Días/mes) }\end{array}$ & Año & $\begin{array}{l}\text { Precipitación } \\
\text { Oribuela } \\
\left(\mathrm{l} / \mathrm{m}^{2}\right)\end{array}$ & $\begin{array}{l}\text { Aforo } \\
\text { Caudal } \\
\left(\mathrm{m}^{3} / \mathrm{s}\right)\end{array}$ & Inundación & $\begin{array}{l}\text { Pérdidas } \\
\text { bumanas }\end{array}$ & $\begin{array}{l}\text { Pérdidas } \\
\text { económicas }\end{array}$ & $\begin{array}{l}\text { Superficie } \\
\text { inundada } \\
\text { ba. }\end{array}$ \\
\hline $20-21 / 02$ & 1992 & 43,3 & - & Segura y otros & 0 & - & $\begin{array}{l}\text { Decenas de } \\
\text { tahúllas en } \\
\text { Almoradí }\end{array}$ \\
\hline $29-30 / 09$ & 1997 & 77 & 250 & Segura y lluvias & 0 & - & - \\
\hline $15-18 / 04$ & 2004 & 78 & - & $\begin{array}{l}\text { Lluvias, acequias y } \\
\text { azarbes }\end{array}$ & 0 & - & Miles de $\mathrm{m}^{2}$ \\
\hline $28-30 / 09$ & 2009 & 190,2 & $\begin{array}{l}60 \text { (Rojales) } \\
100 \\
\text { (Guardamar) }\end{array}$ & $\begin{array}{l}\text { Lluvias, acequias, } \\
\text { azarbes y ramblas }\end{array}$ & 0 & - & - \\
\hline $19-21 / 03$ & 2012 & 47 & 190 & Lluvias & 0 & - & - \\
\hline $28-01 / 10$ & 2012 & 80,6 & 364 & Lluvias y ramblas & 0 & - & - \\
\hline $22-24 / 09$ & 2014 & 30 & 247 & $\begin{array}{l}\text { Lluvias e } \\
\text { inundaciones }\end{array}$ & 0 & - & - \\
\hline $06-10 / 09$ & 2015 & 53,2 & 241 & $\begin{array}{l}\text { Lluvias e } \\
\text { inundaciones }\end{array}$ & 0 & - & - \\
\hline $02-03 / 11$ & 2015 & 40,6 & 215 & $\begin{array}{l}\text { Lluvias e } \\
\text { inundaciones }\end{array}$ & - & - & - \\
\hline $18-21 / 12$ & 2016 & 165 & 437 & Segura y otros & $\begin{array}{l}1 \text { (Benidorm) } \\
1 \text { (Alcázares) }\end{array}$ & - & $\begin{array}{l}\text { Gran parte } \\
\text { de la Vega } \\
\text { Baja }\end{array}$ \\
\hline $19-23 / 04$ & 2019 & 92,2 & 317 & Segura y lluvias & 0 & - & Reguerón \\
\hline $12-15 / 09$ & 2019 & 521 & 450 & Lluvias y Segura & 3 & $1.500 .000 .000 €$ & 25.000 \\
\hline
\end{tabular}

Fuente: Aforos, Confederación Hidrográfica del Segura. Diario Información (1946-2019). Elaboración propia.

A comienzos de noviembre de 1987 se produjo la riada más importante por el Segura en la Vega Baja, desde la inundación del "viernes santo" de abril de 1946. A consecuencia de este episodio el gobierno aprueba, por vía de urgencia, el RDL 4/1987 del 13 de noviembre que pone en marcha el Plan de Defensa de Avenidas de la cuenca del Segura. Tras el evento de noviembre de 1987, el Gobierno recuperaría dicho plan y lo aprueba de forma urgente. A modo de resumen, dichas actuaciones se basaban en la construcción de numerosas presas, canales y encauzamientos o canalizaciones de ramblas. Junto a medidas estructurales y de carácter hidrológico forestal, contempladas en este Plan, se procede, como medida principal, al encauzamiento del río Segura desde su entrada en Orihuela hasta Guardamar del Segura $(35-40 \mathrm{~km})$, suprimiendo y cortando los meandros del río para facilitar la pendiente y velocidad de las aguas en su camino a la desembocadura. Dicho de otras maneras, se buscaba conseguir que el agua del río Segura, en caso de avenida, circulara rápidamente hasta su desembocadura al mar. La capacidad del encauzamiento se realizó para un caudal máximo de $400 \mathrm{~m} 3 / \mathrm{s}$. El total del coste de lasobras a realizar en la cuenca del Segura era de 113.459.065,1 $€$. Las obras de defensa del Plan de Defensa de Avenidas de la Cuenca del Segura comenzarían en 
octubre de 1991. Al año siguiente, se comienzan a observar los muros del encauzamiento del río Segura a su paso por Orihuela. En el año 1997, el encauzamiento se había realizado hasta la entrada de Rojales, quedando así el último tramo desde Rojales hasta su desembocadura en Guardamar del Segura. En octubre del año 2000, el río Segura casi se desborda pudiendo afectar a la Vega Baja. Ese año el encauzamiento del río Segura ya estaba finalizado.

Sin embargo, el primer desbordamiento del río Segura con las obras del encauzamiento del Segura ya plenamente desarrolladas tiene lugar en diciembre de 2016, cuando inunda calles de la ciudad de Orihuela y pedanías próximas al cauce. Se pudo comprobar que la solución de encauzamiento del río Segura presentaba problemas que podían generar desastre en caso de lluvias como las registradas en noviembre de 1987. Unos años antes se había hecho un diagnóstico del aumento del riesgo ocurrido desde la inundación de noviembre de 1987 en la Vega Baja y se había señalado que el caudal de diseño del nuevo cauce del Segura no resultaba suficiente a la vista de los efectos de la crecida ocurrida en octubre de 2000 (Gil Olcina, Olcina Cantos y Rico Amorós, coords., 2004).

Los encauzamientos de cursos fluviales originan sensaciones de falsa seguridad en los territorios donde se realizan (Ollero, 2020). Así ha ocurrido en el tramo bajo del río Segura, lo que puede haber favorecido la ocupación de áreas inundables tras su construcción y la permisividad con la interpretación errónea de la normativa del Patricova (2003) en lo que regula de no ocupación como vivienda de garajes y bajos. Tampoco son frecuentes las actuaciones de limpieza o acondicionamiento anual del tramo bajo del río, produciéndose así la acumulación de sedimentos y de restos de vegetación a lo largo del cauce, que han ido reduciendo la capacidad inicial del encauzamiento. Por último, se ha realizado una gestión, seguramente mejorable, en el mantenimiento de las obras de defensa, con aparición de fenómenos de agrietamiento y fisuras en las motas del encauzamiento desde la finalización de su construcción.

Además de las obras hidráulicas, la comarca ha conocido en las últimas décadas acciones de planificación con objeto de mejorar la resistencia y resiliencia de la comarca ante los peligros naturales (Tabla 3), que han tenido un carácter "sectorial", esto es, han estado orientadas a disminuir el riesgo de un peligro natural específico (inundaciones, sequías, sismicidad). Pero no se ha desarrollado una planificación "integral" que aúne actuaciones orientadas a mejorar la resiliencia de la comarca en relación con la diversidad de peligros naturales que pueden afectar a los diferentes sectores económicos y a los núcleos de población, de forma conjunta.

El presente trabajo tiene como objetivo el estudio de las causas y efectos del episodio de inundación ocurrido en septiembre de 2019 en la comarca de la Vega Baja del Segura, que demostró la necesidad de aplicar medidas diferentes a las propiamente estructurales para la reducción del riesgo y la urgencia de preparar un territorio de riesgo ante los efectos del cambio climático actual que ya manifiesta sus efectos (calentamiento del mar Me- 
diterráneo, intensificación de las precipitaciones). Asimismo, se analiza y valora la respuesta institucional puesta en marcha por el gobierno regional valenciano para adaptar este espacio geográfico a los efectos del cambio climático y la mejora de la resiliencia social, económica y territorial de un espacio geográfico con elevado riesgo natural.

Tabla 3. Acciones de planificación para la mejora de la resistencia y resiliencia de la Vega Baja frente a eventos naturales extremos

\begin{tabular}{|c|c|}
\hline$A \tilde{n} o$ & Acción de planificación \\
\hline 1987 & Plan de defensa de Avenidas de la Cuenca del Segura \\
\hline 1992 & $\begin{array}{l}\text { 1 Plan de Saneamiento y Depuración de Aguas Residuales de la Comunidad } \\
\text { Valenciana }\end{array}$ \\
\hline 2002 & Nueva normativa sismorresistente \\
\hline $1994-95$ & Plan Metasequía \\
\hline 1995 & Programa PAYDES \\
\hline 2001 & Plan Hidrológico Nacional \\
\hline 2002 & PATRICOVA (1 $1^{\underline{a}}$ versión) \\
\hline 2003 & $\begin{array}{l}2^{\circ} \text { Plan de Saneamiento y Depuración de Aguas Residuales de la Comunidad } \\
\text { Valenciana }\end{array}$ \\
\hline 2005 & Programa Agua \\
\hline 2005 & 1ํ Plan de Acción Territorial PAT "Vega Baja". No finalizado \\
\hline 2011 & Plan Especial frente al Riesgo Sísmico en la Comunidad Valenciana \\
\hline 2015 & PATRICOVA ( $2^{\underline{a}}$ versión) \\
\hline 2020 & Plan Vega Renhace \\
\hline $2020-21$ & $2^{\circ}$ Plan de Acción Territorial (PAT) Vega Baja. En tramitación \\
\hline $2020-21$ & $\begin{array}{l}\text { Actuaciones frente a las inundaciones en la Vega Baja del Segura-CHS. } \\
\text { Plan de actuaciones hidráulicas }\end{array}$ \\
\hline
\end{tabular}

Fuente: Elaboración propia.

\section{Fuentes y método}

El análisis de las causas y efectos atmosféricos de la situación que originó la inundación de septiembre de 2019 en la Vega Baja del Segura se ha realizado con la consulta de datos procedentes de fuentes de datos meteorológicos tanto oficiales (Aemet, Laboratorio de Climatología de la UA) como de aficionados (Ametse, Avamet). Los ma- 
pas sinópticos se han consultado del servidor wetterzentrale (www.wetterzentrale.de) en su sección de archivo sinóptico. Los datos hidrológicos consultados proceden de la Confederación Hidrográfica del Segura (CHS), tanto para los episodios históricos que aparecen en la Tabla 2, como para los comentados para el episodio de septiembre de 2019 (red SAIH). De la CHS procede asimismo la documentación consultada sobre planes de defensa de avenidas en la cuenca desde 1940 a la actualidad. Para completar esta información, se ha consultado la hemeroteca de los diarios Información y La Verdad de Murcia para el análisis de los episodios de inundación ocurridos desde 1940 a la actualidad en la comarca del Bajo Segura.

Se han consultado estudios, informes y documentación oficial (planes) sobre la comarca del Bajo Segura, para temas relacionados con sus condiciones del medio físico y el carácter extremo de algunos peligros naturales, así como de actuaciones llevadas a cabo en las últimas décadas para reducir sus efectos.

Se ha incorporado al presente estudio el análisis de la documentación elaborada por el Plan Vega Renhace, plan estratégico puesto en marcha por el gobierno valenciano para la recuperación socio- económica de la comarca y la adaptación al cambio climático. El autor de este trabajo ha tenido una participación en la elaboración de dicho plan ${ }^{1}$.

El método de trabajo del presente artículo ha sido el hipotético-inductivo, a partir del reconocimiento del carácter de riesgo del territorio del Bajo Segura, del análisis de eventos de inundación concretos y de sus efectos, del estudio de las previsiones de cambio climático para la comarca, con el fin de obtener conclusiones que sean de utilidad para la elaboración de propuestas de adaptación y mejora de la resiliencia. Y se abren líneas de trabajo futuras que pueden ser aplicadas en otros territorios de riesgo.

Se ha seguido un procedimiento de estudio basado en el análisis-diagnóstico de la situación territorial existente en la comarca de la Vega Baja del Segura y el impacto de los eventos de inundación ocurridos en las últimas décadas en este espacio geográfico, con especial atención al último ocurrido en septiembre de 2019. Y, en una segunda fase, se valoran las propuestas de actuación para la reducción del riesgo y la adaptación al cambio climático en este territorio contenidas en el plan Vega Renhace. Para ello han sido necesarias las visitas de campo al ámbito de estudio y entrevistas con actores sociales importantes en la comarca, realizadas entre febrero y noviembre de 2019.

1. En noviembre de 2019, el autor de este trabajo fue nombrado "comisionado" del Gobierno Valenciano para el Plan Vega Renhace, con la finalidad principal de la elaboración y gestión posterior del mismo (Decreto 18/2019, de 2 de diciembre, del president de la Generalitat, por el que designa dos comisionados para la coordinación de las actuaciones relacionadas con el Plan Vega Renhace, DOGV no 8692, 5/12/2019). 


\section{Resultados}

La inundación ocurrida en la primera quincena de septiembre de 2019 tuvo por causa atmosférica la instalación de un embolsamiento de aire frío en el espacio sinóptico del sur y sureste ibérico y norte de África. Las lluvias desarrolladas en estas condiciones de alta inestabilidad se vieron incentivadas por la presencia de altas temperaturas en la superficie marina, lo que favoreció la génesis de potentes sistemas nubosos cargados de agua y energía. El proceso hidrológico de la crecida del río Segura y de sus tributarios en el tramo bajo de su curso, encontró un territorio intensamente ocupado y con transformaciones urbanísticas poco acordes con lo racional en un espacio de riesgo. De ahí la magnitud de los efectos ocurridos. La respuesta institucional post-desastre ha sido rápida y pretendidamente eficaz, a partir de la puesta en marcha de un plan estratégico con medidas concretas para la adaptación al cambio climático y la mejora de la resiliencia social y económica de una comarca históricamente afectada por eventos naturales extremos.

\subsection{El episodio de septiembre de 2019: intensidad horaria de las lluvias, rotura del encauzamiento e inundación masiva}

La formación del embolsamiento de aire frío en las capas altas de la atmósfera que originó la inundación de la Vega Baja del Segura a mediados de septiembre de 2019, se fraguó unos días antes en la escena sinóptica. En efecto, el lunes 9 de septiembre una masa de aire polar marítimo desciende en la vertical en forma de vaguada con eje N-S afectando a la península Ibérica. El martes 10 se produce el desgajamiento y la consolidación de una gota fría en el interior de dicha vaguada. El miércoles 11 el núcleo de la gota fría se localizará en la alta troposfera, entre el mar de Alborán y el mar de Argel, situando su sector de salida de vientos (divergencia) sobre el este y sureste de la península Ibérica. Este hecho favorecerá el desarrollo de un proceso ciclogenético mediterráneo con formación de una baja en el mar de Argel. Bolsa de aire frío en las capas altas y desarrollo ciclogenético de Argel en las capas bajas de la troposfera, favorecerán la génesis de potentes núcleos de tormenta bajo la forma de sistemas convectivos de mesoscala, que generarán precipitaciones muy abundantes y de caída intensa entre Castellón y Murcia (Figura 1). Las precipitaciones se extenderán entre el 11 y 15 de septiembre, registrándose las mayores cantidades en la jornada del 12 de septiembre.

Un aspecto resultó fundamental para explicar la cuantía de lluvias registradas durante este episodio de lluvias torrenciales y la intensidad horaria que se alcanzó en algunas localidades de la provincia, afectadas por los núcleos convectivos originados: la temperatura del agua del mar Mediterráneo en los sectores marítimos Balear y de Argel, que había alcanzado 26-27으 C a comienzos de septiembre de 2019, favoreciendo la génesis de los potentes núcleos convectivos que se desarrollan durante las primeras horas de este episodio de fuerte inestabilidad (Figura 2). 


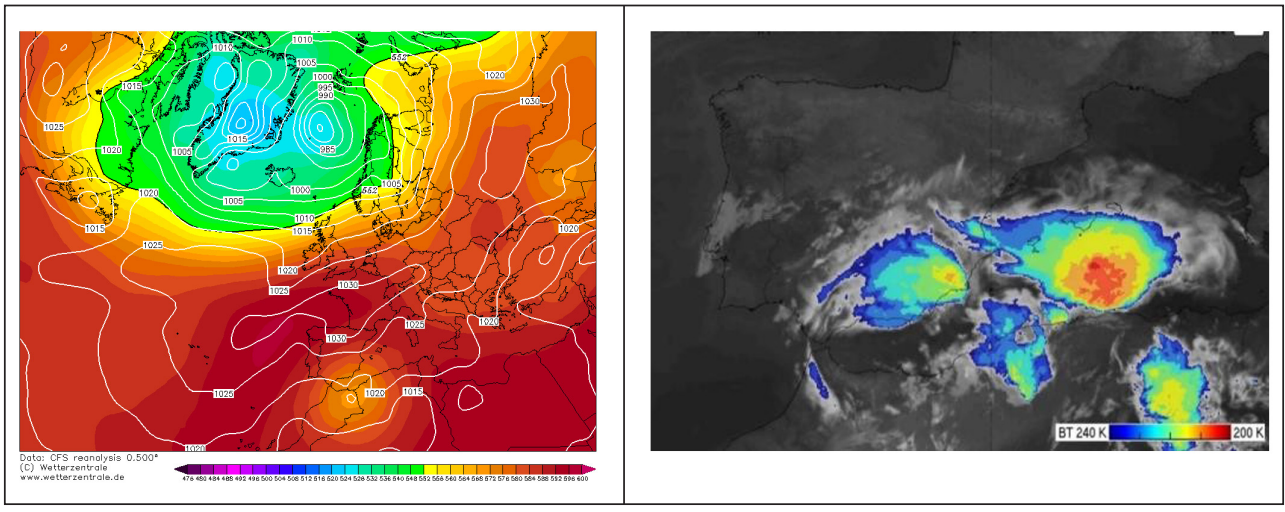

Figura 1. Situación atmosférica del 12/09/2019. Embolsamiento de aire frío en el norte de África y mar de Alborán. Imagen de satélite (canal infrarrojo con falso color) de esta jornada con un potente conjunto convectivo de mesoscala afectando al territorio del sureste peninsular.

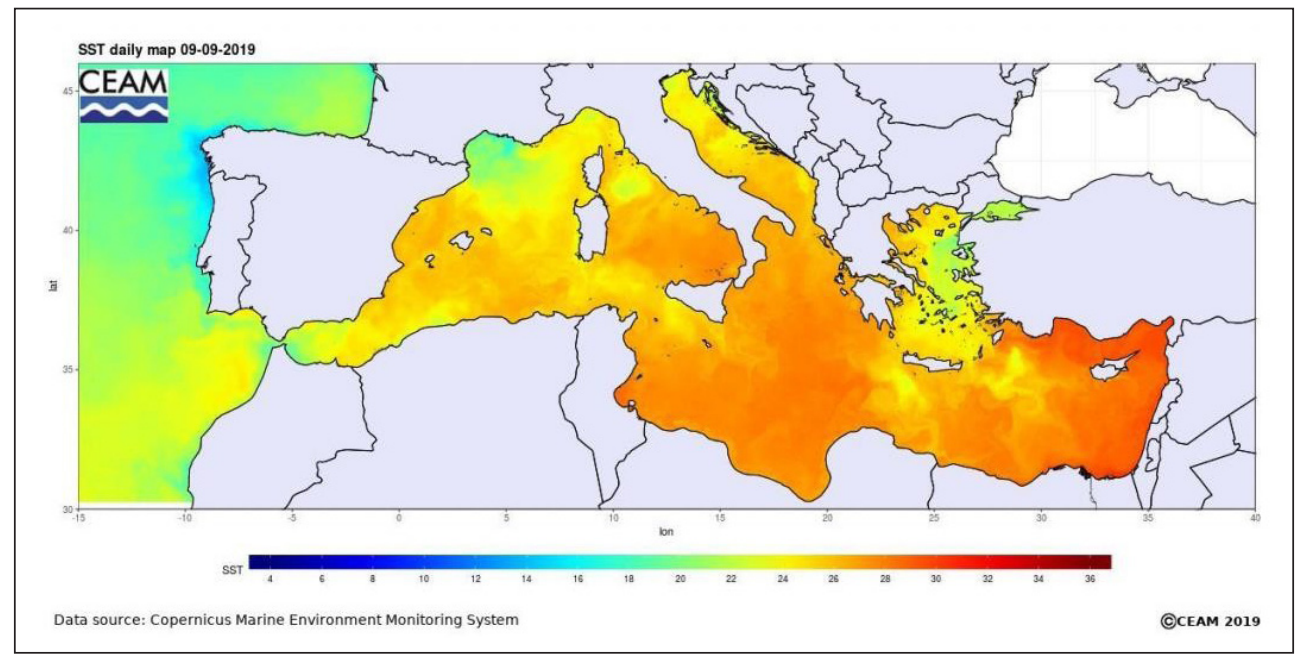

Figura 2. Temperatura del agua del mar Mediterráneo frente a las costas españolas. A principios de septiembre de 2019 se alcanzaron valores de $27^{\circ}-28^{\circ} \mathrm{C}$ en el litoral de Alicante y Murcia. 
A lo largo de la jornada del 12 de septiembre, las tormentas intensas comenzaron en el norte de la provincia de Alicante y sur de Valencia, generando inundaciones importantes y rescatando a personas cuyas viviendas se sitúan en zonas inundables en las localidades de Planes y, especialmente, Ontinyent. Con el paso de las horas de la jornada del 12 de septiembre las lluvias torrenciales, derivadas de la formación de un enérgico sistema convectivo, se concentrarán en el tramo bajo de la cuenca del Segura y litoral murciano del Mar Menor y Campo de Cartagena (Figura 3). En Orihuela se registran 250 l/m2 en tan sólo dos horas (Figura 4). Situación similar aconteció en el resto de la Vega Baja en diferentes localidades.

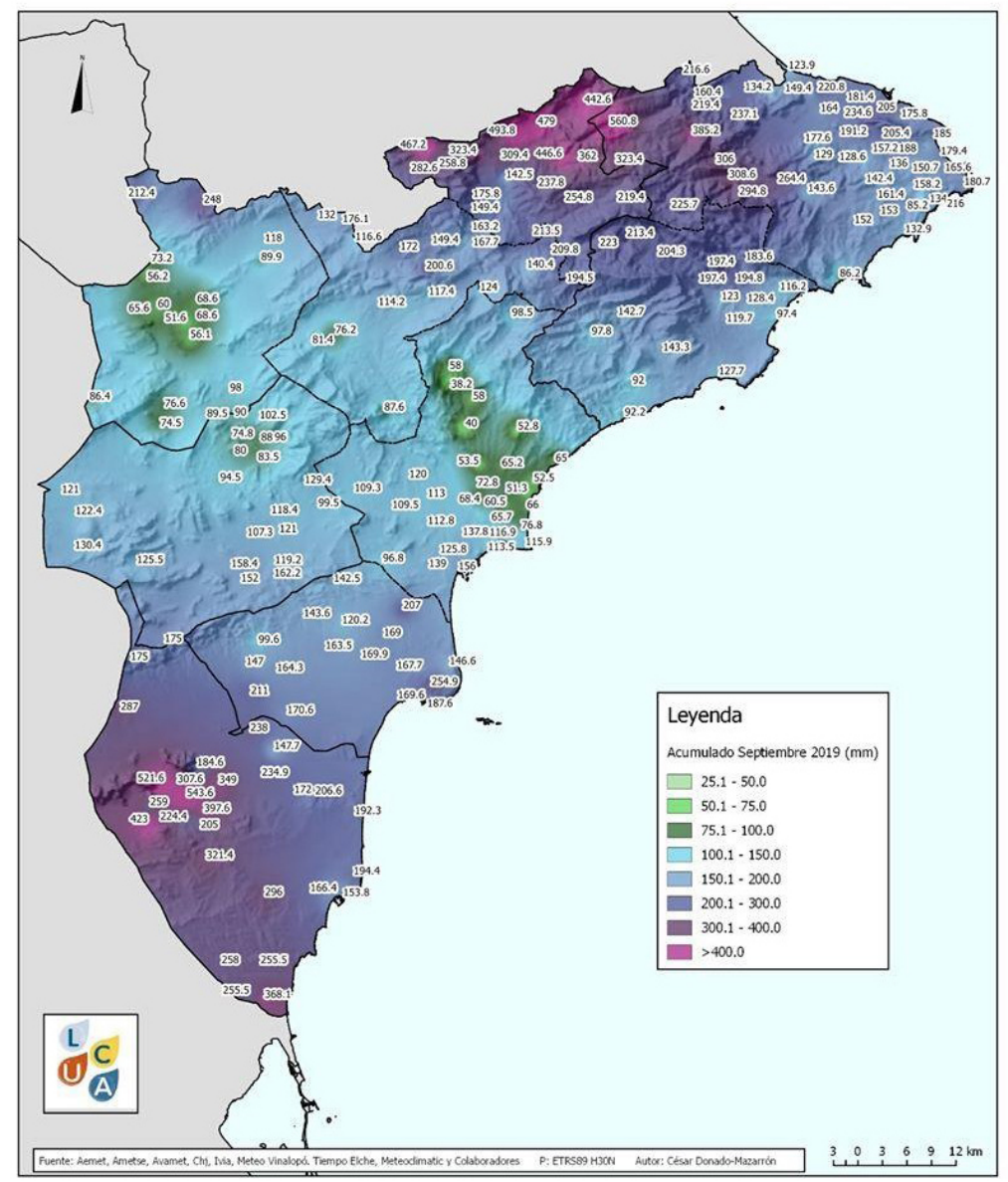

Figura 3. Mapa de precipitaciones recogidas en la provincia de Alicante entre los días 11 y 15 de septiembre de 2019.

Fuente: Laboratorio de Climatología-UA. 


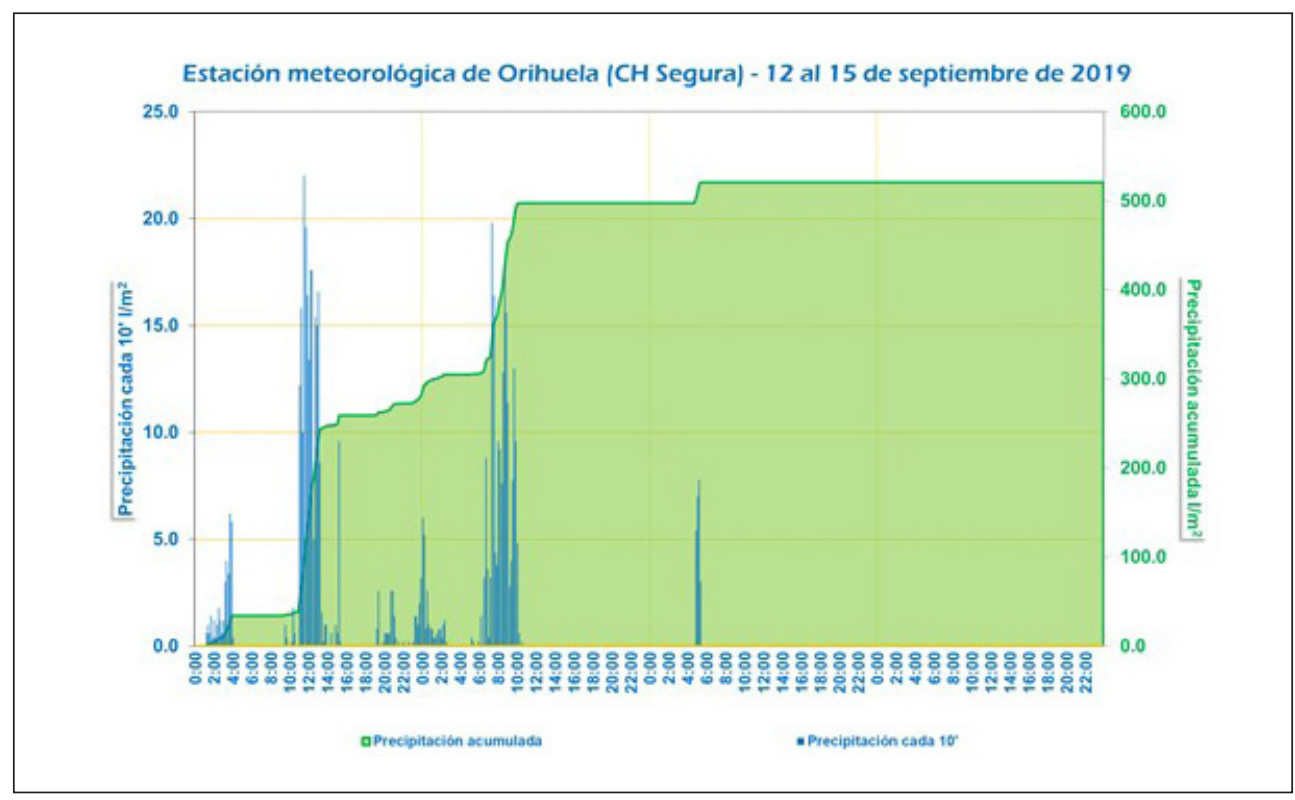

Figura 4. Detalle de la intensidad horaria de la precipitación registrada en Orihuela del 12 al 15 de septiembre de 2019.

Fuente: SAIH. CHS.

Más de seiscientas personas serían rescatadas por las fuerzas de seguridad y los servicios de protección civil y miles de vecinos de la comarca abandonarían sus casas por las inundaciones tras desbordarse el Segura. Por tanto, la Vega Baja estaba inundada, tanto por las trombas de lluvias como por el desbordamiento del río Segura, al romperse el encauzamiento en Almoradí, Benejúzar y Algorfa, anegando otros tantos núcleos urbanos como las Dayas y Dolores, así como enormes extensiones de huerta salpicadas de viviendas que quedaron completamente aisladas. La AP-7 quedó completamente colapsada y cortada en puntos como el túnel de Pilar de la Horadada o el tramo entre Albatera y Granja de Rocamora. Almoradí y Benferri se quedaron sin servicio de agua potable.

El desbordamiento del río Segura a la altura de Almoradí se debió a dos roturas de mota que se produjeron el día 15 de septiembre. Cuando la primera mota se rompió comenzó a inundar la huerta y el polígono industrial de Almoradí, y de ahí en dirección a Dolores quedando inundada por las aguas, junto a las Dayas y San Fulgencio. La Confederación Hidrográfica del Segura comienza a taponar la primera rotura con tierra. Pero cuando ya tenían la rotura tapada, se produjo la segunda rotura unos metros más adelante anegando viviendas que se encontraban prácticamente en los márgenes del río Segura. El agua se dirigió hacia las Dayas inundándolas. A su vez, muchos de las acequias y azarbes se desbordaron ampliando así los campos anegados en la Vega Baja en este episodio. 
La extensión de la lámina de agua sobre la Vega Baja generada por la inundación de septiembre de 2019, superó a la creada tras la inundación de noviembre de 1987 (Figura 5).

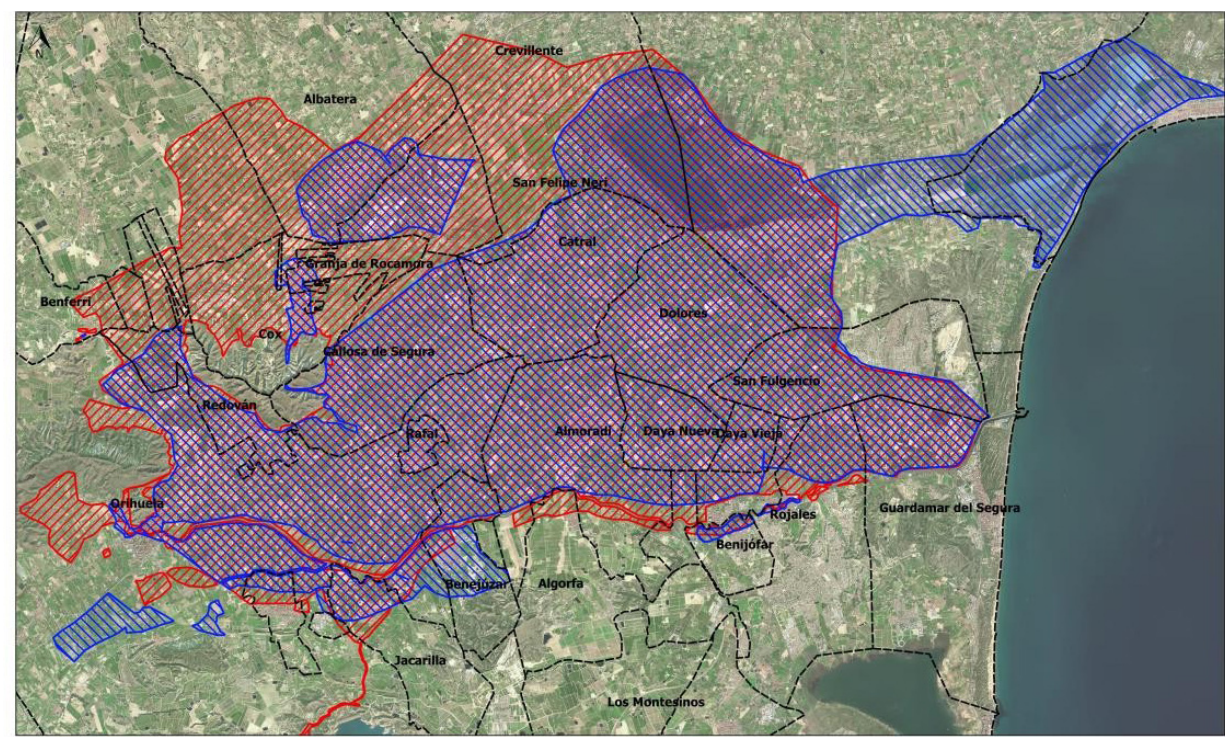

Figura 5.-Extensión de la lámina de agua sobre la Vega Baja del Segura durante el episodio de inundación de septiembre de 2019 (rayado rojo) y comparación con

el ocurrido en noviembre de 1987 (rayado azul).

Fuente: Imágenes de satélite y fotografía aérea.

Elaborado por: Esther Sánchez, Javier Martí, Antonio Oliva y Samuel Biener

El episodio de inundación en la Vega Baja de septiembre de 2019 puso de manifiesto una serie de hechos atmosféricos e hidrológicos que obligan a la actuación territorial para la reducción del riesgo y la adaptación al cambio climático (Tabla 4).

Y a ello hay que sumar las causas territoriales que contribuyeron a agravar los efectos de las lluvias y el desbordamiento del río Segura y de sus tributarios en la comarca y que se resumen en las siguientes cuestiones:

- Ocupación intensa del territorio con urbanizaciones desde 1987 (período de "boom inmobiliario").

- Escaso efecto del PATRICOVA, por la reticencia a actualizar los planes de ordenación urbana municipal.

- Inexistencia de sistemas de evacuación de agua pluvial en los municipios de la comarca. 
Tabla 4. Aspectos "nuevos" atmosféricos e hidrológicos manifestados en el episodio de inundación de septiembre de 2019 en la Vega Baja del Segura

\begin{tabular}{|l|c|}
\hline Aspectos atmosféricos & Aspectos hidrológicos \\
\hline - Intensificación y focalización de las & - Crecida súbita de la rambla de Abanilla con su \\
precipitaciones (Monjó et al., 2016; & abanico aluvial (tramo bajo) ocupado por \\
Olcina 2017; Tamayo y Núñez, 2020) & usos industriales (Marco Molina et al., 2020) \\
- Influencia del calentamiento de las & - Problemas de diseño y construcción en el \\
aguas del mar Mediterráneo (energía & encauzamiento del río Segura. Inexistencia \\
y electricidad en los núcleos & de sistema para flujos de retorno \\
convectivos) (Pastor, 2018) & (Redondo y López, 2020) \\
- Aumento en la frecuencia de & - Acequias y azarbes con escasa capacidad de \\
desarrollo de configuraciones & evacuación de aguas (Benadero et al., 2020) \\
de "gota fría" (Muñoz et al., 2020) & \\
\hline
\end{tabular}

Fuente: Elaboración propia.

- Ausencia de planificación sostenible de escala local y comarcal.

- Sensación de falsa seguridad del encauzamiento realizado tras la inundación de 1987.

- Nuevas infraestructuras viarias (carreteras, ferrocarril) no permeables a los flujos de agua de avenida (obstáculos que agravan el anegamiento).

Además, la comunicación de la emergencia a la población se ha demostrado insuficiente, lo que obliga a modificar los protocolos de actuación de protección civil. Y hay una carencia absoluta de educación para el riesgo en los centros de enseñanza básica de la comarca.

\subsection{La respuesta institucional: el Plan Vega Renhace}

Dos meses después de esta inundación, el Gobierno regional valenciano plantea la idea de elaborar un plan para la reconstrucción-regeneración de la Vega Baja del Segura: el denominado "Plan Vega Baja Renhace" aprovechando el desastre ocurrido como argumento para plantear soluciones e iniciativas que permitan a la comarca ser un referente nacional e internacional en las acciones de adaptación al cambio climático y la reducción de los riegos naturales existentes.

La inundación de septiembre de 2019 evidenció la necesidad de preparar a la comarca de la Vega Baja para que su población y economía puedan resistir de mejor forma los efectos de futuros de episodios similares que puedan ocurrir. Unos extremos atmosféricos que, como señala la modelización climática, pueden ocurrir con mayor frecuencia en las próximas décadas. 
La Vega Baja del Segura es una comarca "resistente" a la peligrosidad natural, no sin consecuencias a veces dramáticas. Porque en este territorio se producen excesos y escasez de agua, terremotos y temporales en la línea de costa. Pero debe convertirse en una comarca "resiliente". En el contexto actual de calentamiento climático los eventos atmosféricos de efectos extremos se presumen más frecuentes, como indica la modelización climática en el litoral mediterráneo español (Cramer, 2018; Aemet, 2019b). Y ello obliga a estar preparados, a adelantarse a los acontecimientos, a que los territorios diseñen programas y actuaciones que preparen a las sociedades que viven en ellos ante los cambios atmosféricos que se prevén y que pueden tener efecto en las actividades económicas y la vida social en su conjunto. Un territorio "resiliente" es aquel que es capaz de recuperarse de forma rápida y aprovechando básicamente sus propios recursos humanos y económicos a los efectos catastróficos causados por el evento extremo, de causa natural o humana.

La finalidad última del Plan Vega Renhace (Generalitat Valenciana, 2020) ha sido convertir la catástrofe en una oportunidad para impulsar un entorno resiliente que favorezca la regeneración económica y social de la Vega Baja, al tiempo que promueva un desarrollo territorial, absolutamente respetuoso con el medio ambiente, que prepare para futuros episodios de temporales, y que posibilite una mayor vertebración del territorio de la Vega Baja con el resto de la Comunitat Valenciana. El Plan Vega Renhace se ha organizado en cuatro pilares fundamentales: coordinación, consenso, evidencia y resiliencia. Pilares que han actuado de hilo vertebrador de la necesidad de aunar esfuerzos de diversos actores, públicos y privados, para la consecución de grandes objetivos comunes (Figura 6).

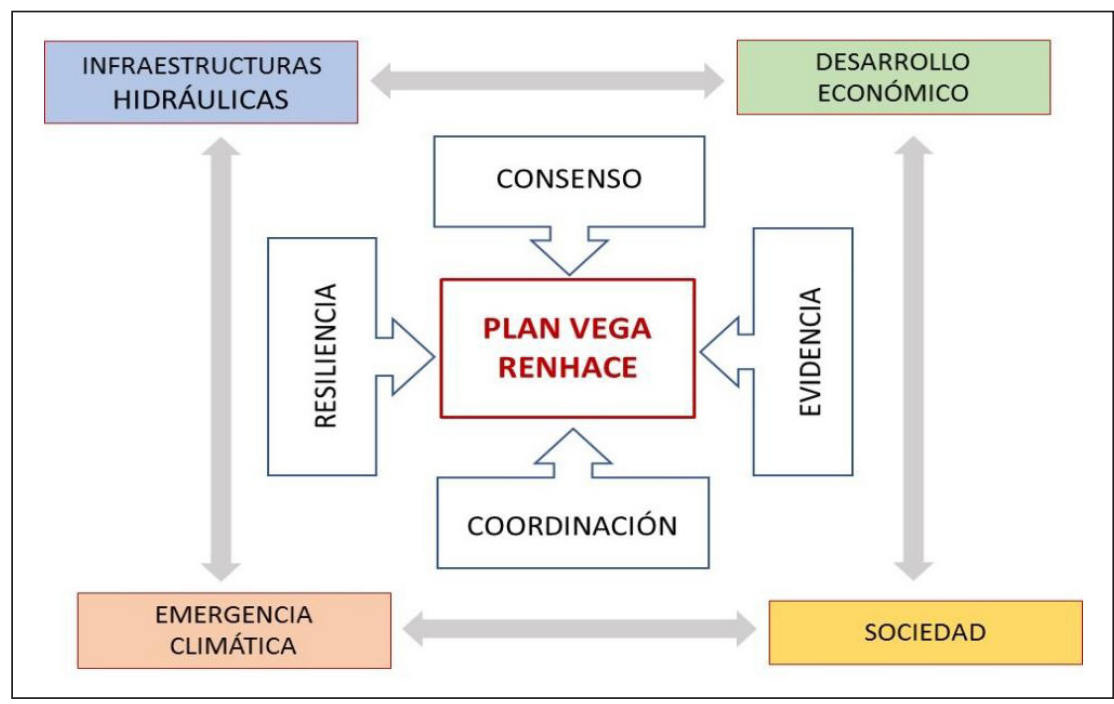

Figura 6. Ejes estratégicos y pilares conceptuales del Plan Vega Renhace.

Fuente: Elaboración propia. 
El consenso entre administraciones y agentes sociales es fundamental porque una iniciativa de estas características incluye acciones que afectan a diferentes escalas administrativas y a diferentes actores sociales y económicos. El plan de participación ciudadana ha sido una pieza básica del plan Renhace. Han sido los ciudadanos, con el apoyo de dos grupos de trabajo (uno de expertos y otro de representación municipal), los que han identificado, propuesto y validado los problemas existentes en su comarca y sus posibles soluciones (Figura 7).
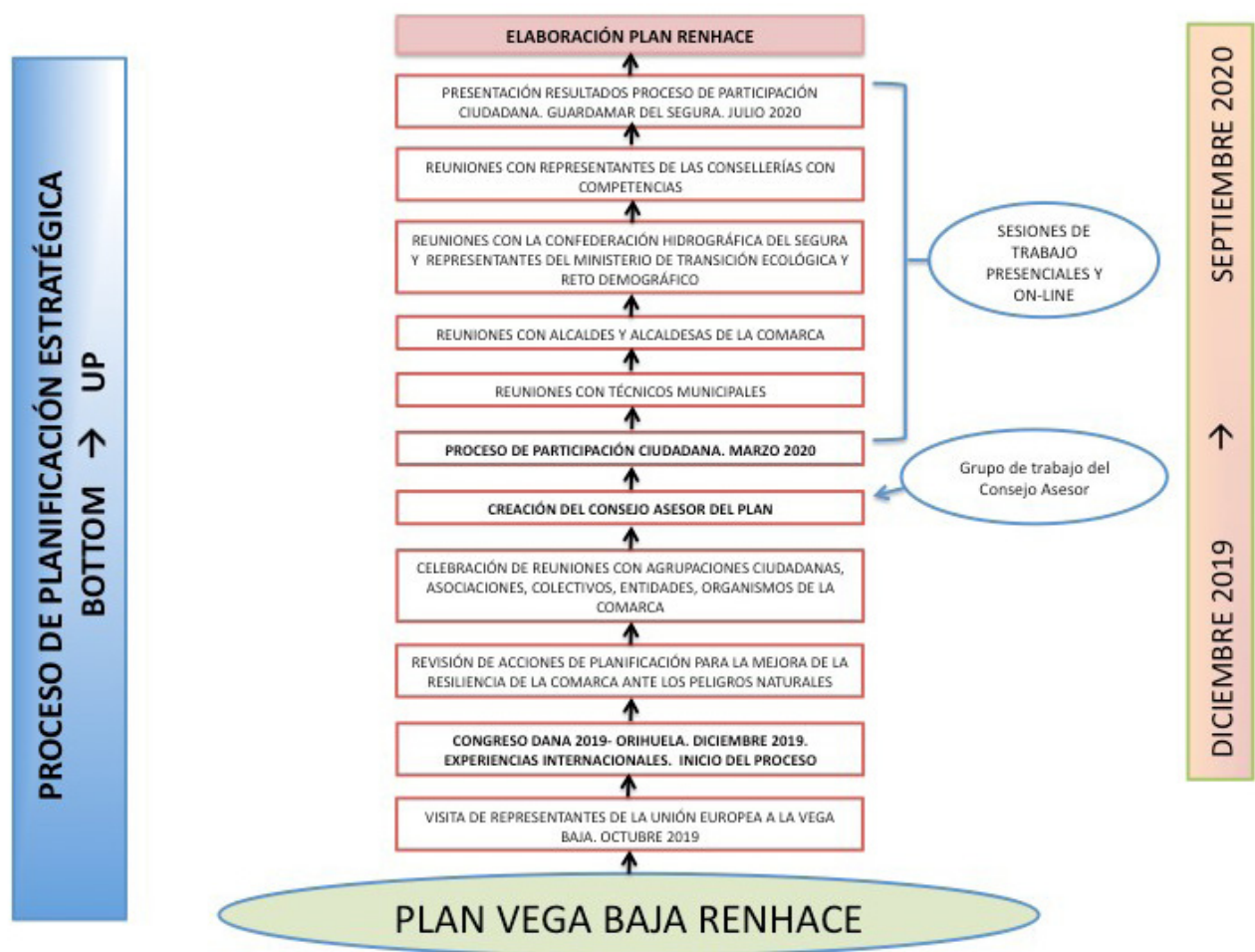

Figura 7. Esquema de desarrollo y participación ciudadana del Plan Vega Baja Renhace.

Fuente: Elaboración propia.

El proceso participativo se diseñó con una doble vertiente: bottom-up (de abajoarriba) y top-down (de arriba-abajo). La vertiente bottom-up ha permitido dotar y empoderar a la ciudadanía con el objetivo de plantear propuestas concretas. La segunda vertiente top-down ha permitido que las administraciones propusieran actuaciones concretas para ser ejecutadas. Ambos procesos se han llevado a cabo simultáneamente y tanto las propuestas surgidas desde el enfoque top-down como bottom-up han sido valoradas y seleccionadas por parte de la ciudadanía. Es decir, se trata de un procedi- 
miento en el que nadie ha dominado el proceso de toma de decisiones. Esta metodología está basada en la filosofía de proceso colaborativo riguroso e inclusivo que tiene la finalidad de elaborar estrategias y planes que permitan la puesta en marcha de proyectos de una determinada comunidad.

El Plan se ha organizado a partir de cuatro ejes de actuación:

- Eje 1. Mejora de las infraestructuras hidráulicas: se plantean actuaciones en el cauce del río Segura y en los cauces problemáticos de la comarca, saneamiento y depuración de aguas, aprovechamiento del agua ante extremos climáticos (inundaciones y sequía) y permeabilidad de las infraestructuras.

- Eje 2. Emergencia climática: se persigue la excelencia en la prevención y gestión de las emergencias y capacidad de reaccionar ante impactos esperables, siendo prioritario la mejora de los sistemas de prevención y alertas, y de los protocolos de actuación.

- Eje 3. Desarrollo económico: se pretende impulsar un ecosistema resiliente que favorezca el desarrollo económico regenerativo, con especial prioridad en materia de agricultura, turismo, comercio e industria, cultura y patrimonio y tecnología.

- Eje 4. Sociedad: actuaciones dirigidas a dar una mayor protección a los colectivos vulnerables, especialmente en materia de vivienda, así como a colaborar a la toma de conciencia de la ciudadanía sobre la realidad del territorio y su relación con un entorno en riesgo por el cambio climático.

De la fase de participación ciudadana surgen ochenta propuestas de actuación para hacer más resiliente el territorio de la Vega Baja del Segura, de las cuales se priorizan veintiocho organizadas en los ejes principales señalados (Tabla 5).

Como se puede comprobar, el 90\% de las actuaciones propuestas en este plan estratégico de ámbito comarcal tienen relación con la ordenación territorial y la planificación de futuros usos económicos, de equipamiento o infraestructura en el espacio de aplicación. La fase de participación ciudadana puso de manifiesto el protagonismo que debe tener el futuro Plan de Acción Territorial de la Vega Baja como documento de planificación territorial normativo que oriente la ordenación de este espacio geográfico bajo los principios de la sostenibilidad y la adaptación a los efectos del cambio climático. 
Tabla 5. Actuaciones prioritarias del Plan Vega Renhace (2020)

\begin{tabular}{|c|c|c|}
\hline Eje & Medida & Actuacion \\
\hline \multirow{10}{*}{ 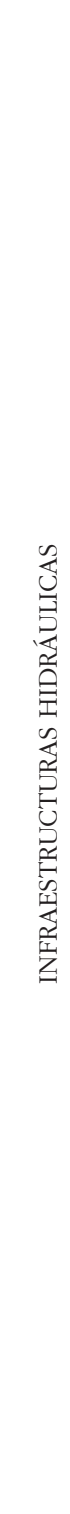 } & \multirow[t]{2}{*}{$\begin{array}{l}\text { Permeabilización de infraestructuras } \\
\text { viarias }\end{array}$} & $\begin{array}{l}\text { ACTUACIÓN \#1 Actuaciones de permeabilización } \\
\text { de infraestructuras viarias y Corredor hidráulico } \\
\text { verde en torno al cauce del Segura }\end{array}$ \\
\hline & & $\begin{array}{l}\text { ACTUACIÓN \#2 Actuación urgente en la N-332 en } \\
\text { la desembocadura del río Segura: permeabilización } \\
\text { del tramo comprendido entre La Marina y } \\
\text { Guardamar del Segura }\end{array}$ \\
\hline & \multirow[t]{3}{*}{$\begin{array}{l}\text { Plan integral de limpieza y mantenimiento } \\
\text { del cauce del rio Segura }\end{array}$} & $\begin{array}{l}\text { ACTUACIÓN \#3 Plan de limpieza integral } \\
\text { del río Segura }\end{array}$ \\
\hline & & $\begin{array}{l}\text { ACTUACIÓN \#4 Acuerdo entre la Confederación } \\
\text { Hidrográfica del Segura y la Federación Valenciana } \\
\text { de Municipios y Provincias para la realización de } \\
\text { actuaciones de limpieza en cauces ubicados } \\
\text { en zona urbana }\end{array}$ \\
\hline & & $\begin{array}{l}\text { ACTUACIÓN \#5 Inversión en la reparación del } \\
\text { mecanismo automático de la pantalla del rio Segura } \\
\text { y proyecto piloto de financiación de la limpieza }\end{array}$ \\
\hline & $\begin{array}{l}\text { Plan de infraestructuras hidráulicas } \\
\text { para la reducción de la peligrosidad } \\
\text { ante las inundaciones }\end{array}$ & $\begin{array}{l}\text { ACTUACIÓN \#6 Convenio de la CHS con la Universitat } \\
\text { Politècnica de València (Departamento de Hidráulica) } \\
\text { para realizar un estudio de inundabilidad } \\
\text { de la cuenca. }\end{array}$ \\
\hline & \multirow[t]{2}{*}{$\begin{array}{l}\text { Actuaciones urbanas sostenibles frente } \\
\text { a inundaciones }\end{array}$} & $\begin{array}{l}\text { ACTUACIÓN \#7 Inversión en sistemas de drenaje } \\
\text { sostenible }\end{array}$ \\
\hline & & $\begin{array}{l}\text { ACTUACIÓN \#8 Creación de "Islas Polder" en } \\
\text { núcleos urbanos de riesgo }\end{array}$ \\
\hline & \multirow[t]{2}{*}{$\begin{array}{l}\text { Garantizar el suministro de agua para } \\
\text { luchar contra la sequía }\end{array}$} & $\begin{array}{l}\text { ACTUACIÓN \#9 Mantenimiento del actual esquema } \\
\text { de dotaciones hídricas para abastecimiento de las } \\
\text { demandas agrarias, industriales y urbano-turísticas) } \\
\text { de la comarca }\end{array}$ \\
\hline & & $\begin{array}{l}\text { ACTUACIÓN \#10 Inversión en la mejora de la } \\
\text { depuración de aguas residuales y su reutilización } \\
\text { para la agricultura y creación de un proyecto } \\
\text { europeo para situar la conversión de todas } \\
\text { las depuradoras de la Comunitat Valenciana } \\
\text { en uso terciario. }\end{array}$ \\
\hline
\end{tabular}




\begin{tabular}{|c|c|c|}
\hline Eje & Medida & Actuacion \\
\hline \multirow{4}{*}{ 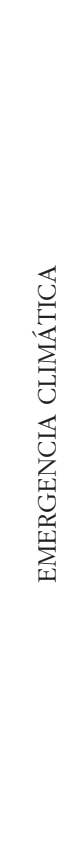 } & $\begin{array}{l}\text { Creación de un Centro de Investigación } \\
\text { de rango europeo en Extremos, } \\
\text { Emergencias y Tecnologías del Agua }\end{array}$ & $\begin{array}{l}\text { ACTUACIÓN \#11 Creación de un Centro de } \\
\text { Investigación de rango europeo en Extremos, } \\
\text { Emergencias y Tecnologías del Agua }\end{array}$ \\
\hline & $\begin{array}{l}\text { Plan de emergencia comarcal y planes } \\
\text { municipales frente a las inundaciones } \\
\text { y el riesgo sísmico }\end{array}$ & $\begin{array}{l}\text { ACTUACIÓN \#12 Implementación de planes de } \\
\text { emergencias para todos los municipios de la } \\
\text { comarca con el empleo de técnicos superiores } \\
\text { en emergencias para su elaboración. }\end{array}$ \\
\hline & $\begin{array}{l}\text { Desarrollo de una aplicación para móviles } \\
\text { (App) de alerta ante el riesgo de } \\
\text { inundaciones dirigida a la ciudadanía }\end{array}$ & $\begin{array}{l}\text { ACTUACIÓN \# } 13 \text { Creación de una app de } \\
\text { Emergencias GVA } \\
\text { ACTUACIÓN \#14 Firma de un acuerdo de } \\
\text { Emergencias GVA con la Universidad de Alicante } \\
\text { para crear una biblioteca de mensajes de riesgo } \\
\text { de inundaciones en la Vega Baja } \\
\text { ACTUACIÓN \#15 Acuerdo Emergencias GVA } \\
\text { y Hidraqua para el uso de una plataforma de big } \\
\text { data para la gestión de los embalses y las inundaciones. }\end{array}$ \\
\hline & $\begin{array}{l}\text { Educación sobre el riesgo de inundación } \\
\text { para ciudadanía }\end{array}$ & $\begin{array}{l}\text { ACTUACIÓN \# } 16 \text { Plan de concienciación, } \\
\text { educación e información ambiental sobre el riesgo } \\
\text { de inundación y sísmico para la ciudadanía } \\
\text { y gestores públicos }\end{array}$ \\
\hline \multirow{6}{*}{ 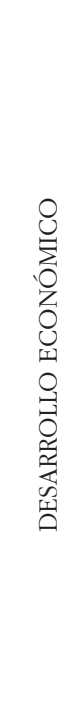 } & $\begin{array}{l}\text { Solución para la CV-95 y movilidad } \\
\text { sostenible de la comarca }\end{array}$ & $\begin{array}{l}\text { ACTUACIÓN \# } 17 \text { Análisis de la movilidad } \\
\text { motorizada y necesidad de actuaciones en la red } \\
\text { viaria de la comarca de la Vega Baja }\end{array}$ \\
\hline & Impulso polígonos industriales & $\begin{array}{l}\text { ACTUACIÓN \#18 Estudio de planeamiento de la } \\
\text { estación intermodal de la Vega Baja en San Isidro, } \\
\text { Alicante }\end{array}$ \\
\hline & \multirow[t]{2}{*}{ Vega Baja parque cultural } & ACTUACIÓN \#19 Proyecto Parque Cultural \\
\hline & & $\begin{array}{l}\text { ACTUACIÓN \#20 Gestión inteligente del patrimonio } \\
\text { cultural }\end{array}$ \\
\hline & \multirow[t]{2}{*}{ Impulso al turismo en la comarca } & $\begin{array}{l}\text { ACTUACIÓN \#21 Plan de dinamización y gobernanza } \\
\text { turística de la Vega Baja }\end{array}$ \\
\hline & & $\begin{array}{l}\text { ACTUACIÓN \#22 Impulso del turismo residencial } \\
\text { en la comarca desde la perspectiva de la sostenibilidad, } \\
\text { enmarcando su crecimiento y desarrollo en la } \\
\text { Agenda Urbana } 2030 \text { y los Objetivos de } \\
\text { Desarrollo Sostenible }\end{array}$ \\
\hline
\end{tabular}




\begin{tabular}{|c|c|c|}
\hline Eje & Medida & Actuacion \\
\hline \multirow{3}{*}{ 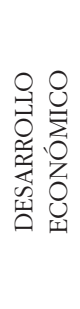 } & $\begin{array}{l}\text { Diversificación de la economía a través } \\
\text { del impulso de sectores tecnológicos }\end{array}$ & $\begin{array}{l}\text { ACTUACIÓN \#23 Puesta en marcha de un Centro } \\
\text { de Economía Creativa y Digital. }\end{array}$ \\
\hline & \multirow[t]{2}{*}{$\begin{array}{l}\text { Impulso al sector agroalimentario y } \\
\text { mejora de los procesos agrícolas mediante } \\
\text { el uso de las nuevas tecnologías }\end{array}$} & $\begin{array}{l}\text { ACTUACIÓN \# } 24 \text { Creación de un Centro de } \\
\text { Investigación Agroalimentaria en el Campus de } \\
\text { Orihuela. }\end{array}$ \\
\hline & & $\begin{array}{l}\text { ACTUACIÓN \#25 Inteligencia artificial aplicada a la } \\
\text { agricultura }\end{array}$ \\
\hline \multirow{3}{*}{ 导 } & Mejora de la red transporte público & $\begin{array}{l}\text { ACTUACIÓN \#26: Plan de Movilidad de la Comarca } \\
\text { de la Vega Baja }\end{array}$ \\
\hline & $\begin{array}{l}\text { Planes de adaptación a las viviendas } \\
\text { existentes en zonas inundables y } \\
\text { su financiación }\end{array}$ & $\begin{array}{l}\text { ACTUACIÓN \#27 Guía virtual para la reducción de la } \\
\text { vulnerabilidad de los edificios frente a las } \\
\text { inundaciones para impulsar un modelo de vivienda } \\
\text { adaptado al entorno y al grado de riesgo y peligrosidad }\end{array}$ \\
\hline & Plan de Acción Territorial de la Vega Baja & $\begin{array}{l}\text { ACTUACIÓN \#28 Plan de Acción Territorial } \\
\text { de la Vega Baja }\end{array}$ \\
\hline
\end{tabular}

Fuente: Plan Vega Renhace. Generalitat Valenciana (2020).

\section{Discusión y conclusiones}

Un episodio de inundación masiva genera daños importantes en los territorios afectados. Las actuaciones de reducción del riesgo deben ir encaminadas a evitar los efectos catastróficos. En los últimos años se ha producido un cambio -necesario- significativo en la gestión del riesgo de inundaciones. Se ha pasado de la apuesta casi única por en la obra hidráulica estructural como pieza principal de las actuaciones de defensa, a concepciones más integrales donde se incluyen aspectos poco valorados hasta hace unos años como la ordenación del territorio, la educación y la comunicación del riesgo. Asimismo, las obras hidráulicas, necesarias en algunos casos, se plantean bajo supuestos de adecuación al medio, incluyendo medidas de recuperación del territorio fluvial. Este último aspecto ha sido trabajado por la Demarcación Hidrográfica del Segura en el plan de actuación de obras hidráulicas que contemplan el desmantelamiento, en algunos tramos, de la obra de canalización del río Segura, para recuperar la ribera fluvial. Las normativas ambientales, de ordenación territorial, del agua y de gestión del riesgo de inundación promulgadas desde Europa y transpuestas a nuestro ordenamiento jurídico han resultado básicas en este cambio conceptual en la gestión del riesgo de inundación.

En la Vega Baja del Segura, el episodio de septiembre de 2019 ha evidenciado, asimismo, este cambio de criterio. Frente a las actuaciones llevadas a cabo tras la inundación de noviembre de 1987, básicamente de carácter hidrológico-estructural, tras la 
inundación de septiembre de 2019 se vio necesario impulsar un programa integral donde las actuaciones hidráulicas fueran un aspecto más en un conjunto de acciones de adaptación territorial al cambio climático (Figura 8).

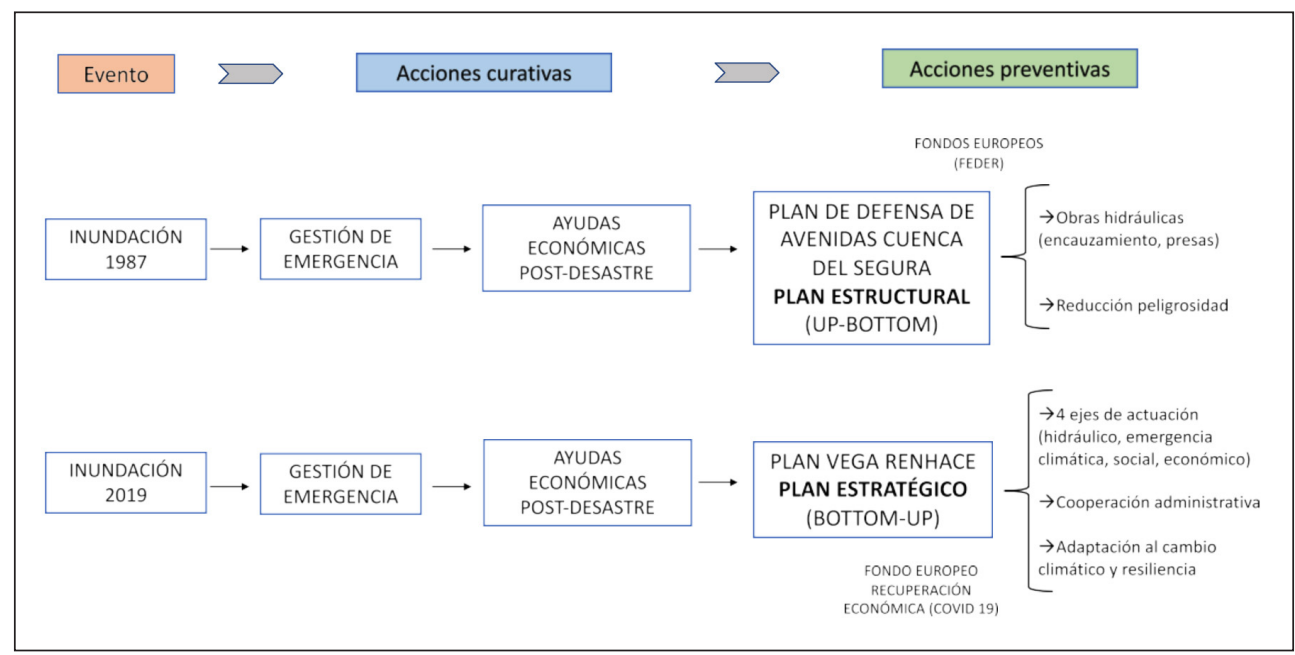

Figura 8. Cambios en la gestión del riesgo de inundación en la Vega Baja del Segura (1987-2019).

Fuente: Elaboración propia.

El contexto actual de cambio climático, con desarrollo muy probable de eventos atmosféricos extremos más frecuentes en latitudes mediterráneas obliga a considerar medidas diversas, complementarias, en los procesos de adaptación de los territorios, puesto que el riesgo va a ser más elevado en las próximas décadas.

El Plan Vega Renhace persigue la adaptación de un territorio de riesgo a las consecuencias del cambio climático para que la respuesta ante un evento extremo, -principalmente lluvias e inundaciones-, sea más rápida porque el propio territorio amortigüe sus efectos.

Los modelos de cambio climático (AEMET, 2019, CEDEX, 2017, Adaptecca, 2020) para este ámbito señalan la intensificación del carácter extremo de la atmósfera, debido a dos factores principales:

- La mayor frecuencia de desarrollo de situaciones inestables en el marco de procesos de reajuste de la atmósfera más enérgicos causados por el calentamiento atmosférico. 


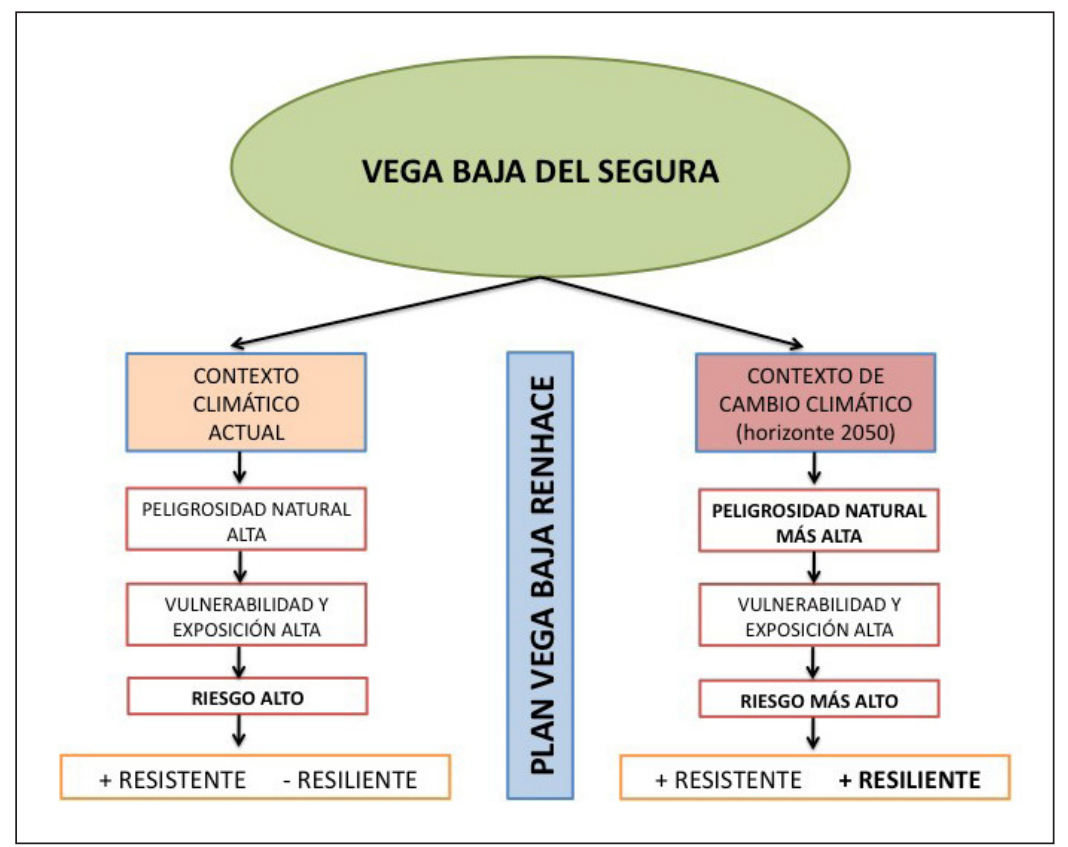

Figura 9. Contexto de la Vega Baja del Segura ante el cambio climático.

Fuente: Elaboración propia.

- El efecto del calentamiento del mar Mediterráneo, como elemento incentivador de procesos de inestabilidad atmosférica y de la intensificación de las precipitaciones.

A las inundaciones debe sumarse el efecto de la reducción de precipitaciones, in situ y en la cabecera del río Tajo (CEDEX, 2017), que debe considerarse en la planificación de recursos hídricos que es un aspecto fundamental en un territorio con escasos recursos de agua autóctonos. El Esquema Provisional de Temas Importantes de la Cuenca del Tajo (2020) esboza tres posibles escenarios que deben tenerse en cuenta para planificar posibles situaciones de desabastecimiento de las demandas existentes en la comarca de la Vega Baja del Segura:

- Si el futuro climático es similar a lo que se está registrando en los últimos años, será posible transferir una media de $410 \mathrm{hm}^{3} /$ año.

- En un escenario de emisiones medias (RCP 4.5), con objetivo de aumento de $1,5^{\circ} \mathrm{C}$ en 2100 , la transferencia se reduciría a $143 \mathrm{hm}^{3} /$ año.

- En un escenario de emisiones altas (RCP 8.5), con subida de temperatura media superior a los $2^{\circ} \mathrm{C}$ en 2100 , sólo sería posible transvasar $100 \mathrm{hm}^{3} /$ año. 
De manera que el mantenimiento del esquema de abastecimiento de agua actual en la comarca (río Segura, acuíferos, trasvase Tajo-Segura, depuración y desalación) debe comenzar a considerar la necesidad de incrementar recursos de agua procedentes de fuentes no convencionales (reutilización y desalación) y aprovechamiento de pluviales para compensar la reducción progresiva de aportaciones desde el Tajo que se registra en los últimos años (Morote et al., 2018).

En síntesis, el impacto del proceso actual de cambio climático de causa antrópica que se manifiesta ya en la región mediterránea va a suponer en la comarca de la Vega Baja del Segura un aumento de la peligrosidad climática, del carácter extremo de los fenómenos atmosféricos y, en consecuencia, del riesgo. Ante ello, son necesarias políticas y prácticas de adaptación para hacer más resistente y resiliente a este territorio. Unas actuaciones que superen la etapa de la apuesta única por las obras estructurales en los cauces fluviales y contemplen acciones con visión integral para el incremento de la resistencia y la resiliencia del territorio, a partir de la planificación sostenible del territorio mediante el uso de la herramienta de la infraestructura verde, la mejora de los protocolos de gestión de la emergencia y la educación y comunicación del riesgo. El plan Vega Renhace es una última oportunidad de la comarca del Bajo Segura de Alicante para reducir el riesgo frente a extremos del agua, para adaptarse al cambio climático y para permitir un desarrollo acorde con el medio en las próximas décadas. Las administraciones tienen la llave de su implementación que debe ser rápida porque las manifestaciones del calentamiento climático ya están ahí.

\section{Agradecimientos}

Conocí personalmente a José María Cuadrat en 1994 en la reunión de climatología que se celebró en La Rábida y que sería el germen del grupo de Climatología de la AGE. Desde entonces nuestra relación, nuestra amistad, no ha dejado de crecer. Siempre me ha atraído su empuje, su ilusión por los nuevos proyectos, su talante abierto, su capacidad de diálogo, su amplitud de miras, su visión de largo plazo, su confianza en lo colectivo, su apuesta por la geografía como disciplina capaz de solucionar problemas en la sociedad. Referencia en la climatología española y geógrafo integral e íntegro. Con profundo agradecimiento por su labor y amistad en todos estos años.

\section{Bibliografía}

AEMET (2019a). "Datos Abiertos. AEMET Open Data". Agencia Estatal de Meteorología, Ministerio para la Transición Ecológica y el Reto Demográfico. Disponible en: http://www.aemet.es/ es/serviciosclimaticos/cambio_climat [Última consulta: 29/12/2020] [En Línea].

AEMET (2019b). "Proyecciones climática para el siglo XXI en España". Agencia Estatal de Meteorología, Ministerio para la Transición Ecológica y el Reto Demográfico. Disponible en: http://www.aemet.es/es/serviciosclimaticos/cambio_climat [última consulta: 29/12/2020] [En Línea]. 
AEMET (2019). "Atlas Climático Ibérico". Agencia Estatal de Meteorología, Ministerio de Medio Ambiente y Medio Rural y Marino, 80 p. ISBN: 978-84-7837-079-5.

Asociación Valenciana de Aficionados a la Meteorología (AVAMET) (2019). "Estadísticas y Meteored Fechas históricas” Disponible en: https://www.avamet.org/mx-meteoxarxa.php [Última consulta: 27/12/2020] [En Línea].

Ariño Villaroya, A. (Dir.) y Garcia Pilan, P. (coord.) (2019). La sociedad valenciana en transformación (1975- 2025). Publicaciones de la Universitat de València, Valencia, 594 p.

Benadero García Morato, J.V.; Muguruza Oxinaga, P.I. y Marín Abdilla, J. (2020). "Estado del riesgo de la Vega Baja del río Segura frente a inundaciones. Necesidad de realizar un plan de in-

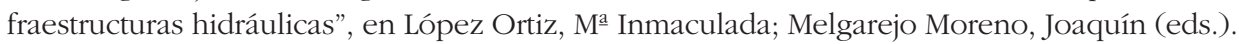
Riesgo de inundación en España: análisis y soluciones para la generación de territorios resilientes. Alacant: Universitat d'Alacant, pp. 591-610.

Biener, S. (2020). "Confirmado, las DANAs están aumentando de forma notable en Europa", Tiempo.com, 20 de febrero de 2020. Disponible en: https://www.tiempo.com/noticias/actualidad/gotas-frias-danas-son-mas-habituales-desde-1960-espana.html (Consultado: 28/ 02/2020).

Burriel de Orueta, E.L. (2008). La década prodigiosa del urbanismo español (1997-2006). Scripta Nova. Revista Electrónica de Geografía y Ciencias Sociales. [En línea]. Barcelona: Universidad de Barcelona, 2008, vol. XII, no 270 (64). http://www.ub.es/geocrit/sn/sn-270/sn-270-64.htm

Canales Martínez, G. (dir.) (1995). "El Bajo Segura. Estructura espacial, demográfica y económica". Alicante: CAM Fundación Cultural; Universidad de Alicante, 312 p. ISBN: 84-600-9097-3.

CEDEX, (2017). Evaluación del impacto del cambio climático en los recursos hídricos y sequías en España, Madrid. Ministerio de Agricultura y Pesca, Alimentación y Medio Ambiente y Ministerio de Fomento, 346 p.

Comisión Europea (2016) Supporting the Implementation of Green Infrastructure. Final Report. Rotterdam, 203 p.

Comité de Desarrollo Territorial (1999). Estrategia Territorial Europea. Hacia un desarrollo equilibrado y sostenible del territorio de la UE. Comisión Europea, Luxemburgo, 89 p. Disponible en: http://ec.europa.eu/regional_policy/sources/docoffic/official/reports/pdf/sum_es.pdf

Consellería de Vivienda, Obras Públicas y Vertebración Del Territorio (2018). Plan de Acción Territorial de la Infraestructura Verde del litoral. Consultado en: http://www.habitatge.gva.es/ es/web/planificacion-territorial-e-infraestructura-verde/plan- de-accion-territorial-de-la-infraestructura-verde-del-litoral

Cramer W.; Guiot J.; Fader, M.; Garrabou, J.; Gattuso, J.P.; Iglesias, A.; Lange, M.A.; Lionello, P.; Llasat, M. C.; Paz, S.; Penuelas, J.; Snoussi, M.; Toreti, A.; Tsimplis, M.N.; Xoplaki, E. (2018). "Climate change and interconnected risks to sustainable development in the Mediterranean". Nature Climate Change 8, pp. 972-980.

De Luis, M.; Brunetti, M.; Gonzalez-Hidalgo, J.C.; Longares, L.A.; Martin-Vide, J. (2010). "Changes in seasonal precipitation in the Iberian Peninsula during 1946-2005", Global and Planetary Change 74 (1), pp. 27-33. 
Demarcación Hidrográfica del Segura (DHS) (2020). "Sistemas Automáticos de Información Hidrológica (SAIH)" Ministerio para la Transición Ecológica y el Reto Demográfico. Disponible en: https://www.chsegura.es/chs/cuenca/redesdecontrol/SAIH/ [Última consulta: 27/01/2020] [En Línea].

Demarcación Hidrográfica del Segura (DHS) (2020). "Cronología de riadas en la cuenca del río Segura (1259- 2012)" Ministerio para la Transición Ecológica y el Reto Demográfico. Disponible en: https://www.chsegura.es/chs/informaciongeneral/elorganismo/unpocodehistoria/riadas.ht ml [última consulta: 27/01/2020] [En Línea].

Demarcación Hidrográfica del Tajo (2020). Esquema Provisional de Temas Importantes. Tercer ciclo de planificación hidrológica. Disponible en: http://www.chtajo.es/LaCuenca/Planes/ PlanHidrologico/Planif_2021-2027/Documents/PHT3_EpTI_01-2020.pdf. Consultado: enero 2021.

Diario Información. Hemeroteca (1940-2020).

Elorrieta, B.; Olcina, J.; Sánchez, D. (2016). La sostenibilidad en la planificación territorial de escala regional. Cuadernos Geográficos 55 (1), pp. 149-175.

Espon (2014). European Land Use Patterns. Applied Research. Final Report. European Union. ESPON Coordination Unit, Luxembourg, 82 p. Disponible en: https://www.espon.eu/programme/ projects/espon-2013/applied-research/eu-lupa- european-land-use-patterns

Farinós Dasi, J. (ed. y coord.) (2011). La gestión integrada de zonas costeras, ¿̇Algo más que una ordenación del litoral revisada?, Publicaciones de la Universitat de València, Valencia, 376 p.

Gaja i Díaz, F. (2008). El "tsunami urbanizador" en el litoral mediterráneo. El ciclo de hiperproducción inmobiliaria 1996-2006. Scripta Nova. Revista electrónica de Geografía y Ciencias Sociales, [En línea] Barcelona: Universidad de Barcelona, vol. XII, no 270 (66). http://www.ub.es/ geocrit/sn/sn-270/sn-270-66.htm

Generalitat Valenciana (2018). Plan de Acción Territorial de Infraestructura Verde del Litoral de la Comunidad Valenciana (PATIVEL), 168 p., Valencia, Consellería de Política Territorial, Obras Públicas y Movilidad. http://politicaterritorial.gva.es/es/web/planificacion-territorial-einfraestructura- verde/plan-de-accion-territorial-de-la-infraestructura-verde-del-litoral

Generalitat Valenciana (2020). Plan Vega Rehace. Una estrategia integral para la resiliencia de la comarca de la Vega Baja del Segura, 98 p., Valencia, Dirección General de Análisis y Políticas Públicas. http://www.presidencia.gva.es/es/web/vega-renhace

Gil Olcina, A. y Canales Martínez, G. (2007). "Residuos de propiedad señorial en España. Perduración y ocaso en el Bajo Segura". Universidad de Alicante.

Gil Olcina, A. y Olcina Cantos, J. (Ed.) (2017). "Tratado de Climatología” Instituto Interuniversitario de Geografía. Universidad de Alicante, 950 p.

Intergovernmental Panel on Climate Change (IPCC) (2013-2014). Climate Change 2013: The Physical Science Basis. Contribution of Working Group I to the Fifth Assesment Report of the Intergovernmental Panel on Climate Change.

IPCC (2018). Special Report on Global Warming of $1.5^{\circ} \mathrm{C}$. Contribution of Working Group I to the Fifth Assesment Report of the Intergovernmental Panel on Climate Change (AR5). Disponible en: https://www.ipcc.ch/sr15/ 
IPCC (2019). Special Reporton Climate Change, Desertification, Land Degradation, Sustainable Land Management, Food Security, and Greenhouse gas fluxes in Terrestrial Ecosystems. Contribution of Working Group I to the Fifth Assesment Report of the Intergovernmental Panel on Climate Change (AR5) Disponible en: https://www.ipcc.ch/report/srccl/

IPCC (Intergovernmental Panel on Climate Change) (2014). Climate Change 2013 and Climate Change 2014 (3 vols.). Available on: http://www.ipcc.ch/

IPCC (Intergovernmental Panel on Climate Change) (2018). Global Warning of 1,5ํ․ Special Report. Available on: https://www.ipcc.ch/sr15/

López Ortiz, Mª I.; Melgarejo Moreno, J. (eds.) (2020). Riesgo de inundación en España: análisis y soluciones para la generación de territorios resilientes. Alacant: Universitat d'Alacant, 1329 p.

Losada, I.; Izaguirre, C. y Diaz, P. (2014). Cambio climático en la costa espanola. Oficina Espanola de Cambio Climático, Ministerio de Agricultura, Alimentación y Medio Ambiente. Madrid, 133 pág. Disponible en: https://www.adaptecca.es/sites/default/files/documentos/ 2014_informe_c3e_final_cambi o_climatico_en_la_costa_espanola.pdf.

Marco Molina, J.A.; Giménez Font, P.; Padilla, A.; García-Botella, E. y Prieto Cerdán, A. (2020). "La rambla de Abanilla-Benferri como paradigma para el estudio del conocimiento tradicional relativo al aprovechamiento de las aguas de avenida". En: López Ortiz, M ${ }^{a}$ Inmaculada; Melgarejo Moreno, Joaquín (eds.). Riesgo de inundación en España: análisis y soluciones para la generación de territorios resilientes. Alacant: Universitat d'Alacant, pp. 881-896.

Millán, M., Estrela, $M^{\underline{a}}$ J. and Miró, J.J. (2005). Rainfall components: variability and spatial distribution in a Mediterranean area (Valencia region). Journal of Climate, 18(14), pp. 2682-2705. https://doi.org/10.1175/JCLI3426.1

Miró Pérez, J. (2014). Downscaling estadístico de series climáticas mediante redes neuronales: reconstrucción en alta resolución de la temperatura diaria para la Comunidad Valenciana. Interpolación espacial y análisis de tendencias (1948-2011). Tesis doctoral. Universidad de Alicante, DOI: 10.13140/RG.2.1.2059.1523.

Miró Perez, J. J.; Estrela Navarro, Mํㅗ J. y Olcina Cantos, J. (2016). "Reconstrucción de la senal térmica local en la Comunidad Valenciana entre 1948 y 2011 a partir de un downscaling estadístico mediante una red neuronal artificial: detección de patrones locales de cambio", $B A G E$ no 70 , pp. 113-147.

Monjo, R. and Martín-Vide, J. (2016)."Daily precipitation concentration around the world according to several indices", International Journal of Climatology, 36(11), pp. 3828-3838. https:// doi.org/10.1002/joc. 4596.

Morote, A., Olcina J. y Rico, A.M. (2018). "Un trasvase cuestionado: el Tajo-Segura. Repercusiones socio-económicas en el sureste espanol e incertidumbre ante el cambio climático", Revista de Estudios Regionales, 113, pp. 29-70.

Muñoz, C.; Schultz, D. y Vaughan, G. (2020). "A Midlatitude Climatology and Interannual Variability of 200- and 500-hPa Cut-Off Lows". American Meteorological Society.

Olcina Cantos, J. (2012)."Globalisation and Sustainability: Threats to the environment in a globalised world. The point of view of Spanish geography”. En: Comité Español de la Unión Geográfica Internacional. New trends in the XXI century Spanish Geography. Madrid. Comité Español de la UGI, pp. 374-392. 
Olcina Cantos, J. (2013). "Experiences in adapting to Climate Change and Climate Risk in Spain", in Climate Change Adaptation in practice: from strategy development to implementation. New Jersey: Wiley-Blackwell, pp. 253-268.

Olcina Cantos, J. (2020). "Clima, cambio climático y riesgos climáticos en el litoral mediterráneo. Oportunidades para la geografía”, Documents de Analisi Geografica, 66/1, pp. 159-182.

Olcina Cantos, J. y Moltó Mantero, E. (eds.) (2019). "Climas y tiempos del País Valenciano. Publicaciones de la Universidad de Alicante, 180 p. ISBN: 978-84-9717-659-0.

Olcina Cantos, J.; Hernández Hernández, M.; Rico Amorós, A.M.; Martínez Ibarra, E. (2010). "Increased risk of flooding on the coast of Alicante (Region of Valencia, Spain)", Natural Hazards, vol. 10, no 11, pp. 2229-2234.

Ollero Ojeda, A. (2020). "Crecidas, inundaciones y resiliencia” en López Ortiz, Mํa Inmaculada; Melgarejo Moreno, Joaquín (eds.). Riesgo de inundación en España: análisis y soluciones para la generación de territorios resilientes. Alacant: Universitat d'Alacant, pp. 549-568.

Padilla Blanco, A., Prieto Cerdán, A., Marco Molina, J.A., Giménez Font, P., y Sánchez Pardo, Á. (2019). "El papel del inventario ambiental exhaustivo en el proceso de la configuración definitiva de la Infraestructura Verde del litoral sur de la Comunitat Valenciana", Boletín de la Asociación de Geógrafos Españoles, 82, 2805, pp. 1-37. http://dx.doi.org/10.21138/bage.2805

Pastor, F.; Valiente, J.A.; Palau, J.L. (2018). "Sea Surface Temperature in the Mediterranean: Trends and Spatial Patterns (1982-2016)", Pure Appl Geophys 175: pp. 4017-4029. https://doi.org/ $10.1007 /$ s00024-017-1739-Z

Redondo Orts, J.A.; López Ortiz, M.I. (2020)."Gestión del riesgo de inundación en la planificación hidrológica de la Demarcación Hidrográfica del Segura”, en López Ortiz, Mํaㅡ. Inmaculada; Melgarejo Moreno, Joaquín (eds.). Riesgo de inundación en España: análisis y soluciones para la generación de territorios resilientes. Alacant: Universitat d'Alacant, pp. 787-796.

Romero González, J. (2011)."Construcción residencial y gobierno del territorio en España. De la burbuja especulativa a la recesión. Causas y consecuencias", Cuadernos Geográficos de Granada, 47, pp. 17-46.

Rullan, O. (2012). Urbanismo expansivo en el Estado español: de la utopía a la realidad. En E. V. Gozálvez y J.A. Marco, Geografía. Retos ambientales y territoriales (p. 165-209). Alicante: Universidad de Alicante. Disponible en: http://citywiki.ugr.es/w/images/6/6f/2012_ORullan _AGE_Alacant.pdf

Sauri, D.; Olcina, J.; March, H.; Martín-Vide, J.; Vera, F., Padilla, E. and Serra-Llobet, A. (2013). "Tourism, Climate Change and Water Resources: Coastal Mediterranean Spain as an Example", in European Climate Vulnerabilities and Adaptation: A Spatial Planning Perspective, Publisher: John Wiley \& Sons, Ltd, Editors: Philipp Schmidt-Thomé, Stefan Greiving, pp. 231- 252.

Serrano Notivoli, R. (2017). Reconstrucción climática instrumental de la precipitación diaria en España: ensayo metodológico y aplicaciones. Tesis doctoral, inédita. Universidad de Zaragoza. Facultad de Filosofía y Letras. Departamento de Geografía y Ordenación del Territorio. Zaragoza, 234 pp. + anexo cartográfico (inédita).

Silva, P.D.; Elez, J.; Giner-Robles, J.L.; Pérez-López, R; Roquero, E.; Rodríguez-Pascua, M.A.; Bardaji, M‥T.; Martínez-Graña, A.M. (2019). Análisis geológico del terremoto de Torrevieja de 1829 (Alicante, SE España). XV Reunión Nacional de Cuaternario Bizkaia Areloa. Bilbao, pp. 434-437. 
Tamayo Carmona, J. y Núñez Mora, J.A. (2020). "Precipitaciones intensas en la comunidad valenciana. Análisis, sistemas de predicción y perspectivas ante el cambio climático" en Riesgo de inundación en España: análisis y soluciones para la generación de territorios resilientes (coord. por Inmaculada López Ortiz, Joaquín Melgarejo Moreno); Universidad de Alicante, pp. 49-62.

Torres Alfosea, F.J. (2010). "Cuarenta años de leyes de costas en España (1969-2009)", Investigaciones geográficas, n⿳0 52, pp. 167-200.

Vera Rebollo, J.F. y Espejo Marín, C. (2006). El papel de los instrumentos de planificación en las dinámicas productivas y territoriales: las Directrices y Plan de Ordenación del Litoral de la Región de Murcia, en Romero, J y Farinós, J. (eds): Gobernanza territorial en España. València: Publicacións de la Universitat de València, pp. 61-79.

Vera-Rebollo, J.F. y Olcina Cantos, J. (2017). Análisis de la coherencia metodológica y de los datos utilizados en la memoria justificativa del PATIVEL. Conselleria de Vivienda, Obras Públicas y Vertebración del Territorio de la Generalitat Valenciana, Universidad de Alicante, 127 pp. (inédito).

Vera-Rebollo, J.F.; Olcina Cantos, J. y Sainz-Pardo Trujillo, A. (2019). "La incorporación de la infraestructura verde en la ordenación territorial. El plan de acción territorial de la infraestructura verde del litoral de la Comunidad Valenciana, PATIVEL", Ciudad y Territorio. Estudios Territoriales, vol. LI, nº 200, 467-490.

Vicente-Serrano, Sergio; Azorín-Molina, César; Peña-Gallardo, Marina; Tomas-Burguera, Miquel; Domínguez-Castro, Fernando; Martín-Hernández, Natalia; Beguería, Santiago; Kenawy, Ahmed El; Noguera, Iván; and García, Monica (2019). "A high-resolution spatial assessment of the impacts of drought variability on vegetation activity in Spain from 1981 to 2015", Natural Hazards and Earth System Sciences. 19. 1189-1213. 10.5194/nhess-19-1189-2019.

VV.AA. (2013). Manifiesto por la preservación y gestión de los espacios costeros. Asociación de Geógrafos Españoles. Madrid, 7 p. Disponible en: http://www.age-geografia.es/site/wp- content/ uploads/2015/01/costas_version_final.pdf (Consultado: agosto 2018).

Wetterzentrale (2020). Archivo. Reanálisis CFSR (1979-Actualidad). Disponible en: https://www. wetterzentrale.de/es/reanalysis.php?map $=1$ \&model $=\mathrm{cfsr} \& v a r=1$ 
